\title{
Review of nuclear data for naturally occurring radionuclides applied to environmental applications
}

\author{
Alan J. Cresswell ${ }^{\text {, }}$ David C.W. Sanderson, and John Carter \\ Scottish Universities Environmental Research Centre, East Kilbride G75 0QF, UK
}

Received: 15 December 2017 / Revised: 29 November 2018

Published online: 19 February 2019

(C) The Author(s) 2019. This article is published with open access at Springerlink.com

\begin{abstract}
Accurate nuclear data, commonly using evaluated libraries, is essential in many applications, allowing confidence in derived parameters. An approach to assess the confidence with which these data can be used is proposed, not previously reported, comparing nuclear data presented by different evaluations. Variations between evaluations are used as an indication of potential inaccuracies in the nuclear data or evaluation procedure, and the relevant primary literature reviewed more fully. Applying this approach to naturally occurring radionuclides has identified eight radionuclides where the evaluations differ significantly. Where recommended data are supported by a single set of high precision measurements, independent verification of those measurements will increase confidence in the accuracy of the data $\left({ }^{214} \mathrm{Bi}\right.$ and $\left.{ }^{214} \mathrm{~Pb}\right)$. Further measurements should be conducted where the decay schemes are incomplete $\left({ }^{228} \mathrm{Ac}\right.$ and $\left.{ }^{228} \mathrm{Ra}\right)$. For ${ }^{40} \mathrm{~K}$, the mean beta energy in all the evaluations has been calculated using an incorrect shape factor, and $\log f t$ and branching ratios have been calculated using an inappropriate program. Precise measurements of beta spectra will allow the use of experimentally derived shape factors for the calculation of mean beta energies $\left({ }^{40} \mathrm{~K}\right.$ and $\left.{ }^{210} \mathrm{Bi}\right)$. Parameters used for infinite matrix dose rate and geothermal heat production calculations have been derived for the data discussed here.
\end{abstract}

\section{Introduction}

The determination of dose rates and other parameters from radionuclide concentrations is essential to many fields of investigation, such as studies of radiation exposure on the health of humans and ecosystems, optimising exposure for radiotherapy, estimating geothermal potential, and stored dose dating. Dose rates can be measured directly using field instruments or passive dosimeters. But it is often necessary to determine dose rates from radionuclide concentration data determined from samples returned to the laboratory, either in the absence of direct dose rate measurements or to supplement other measurements, requiring parameters to convert measured activity concentration to dose rate. In geochronology accurate values of the half lives, and in some cases branching ratios, of radionuclides are also essential. Assessments of geothermal potential, and similar applications requiring calculations of heat production in rocks, require parameters derived from the total energy released during radioactive decay. Parameters for these, and other applications, are derived from nuclear decay data (tabulations of the energy and intensity of nuclear radiations, branching ratios and half lives).

The accuracy of these parameters will depend on several factors, including the accuracy of the nuclear data used. Many practitioners using this data will take it on trust that the data reported are accurate with appropriate uncertainties. It has recently been noted in relation to evaluation of neutron data standards [1] that earlier evaluations had rather small uncertainties leading to an investigation of unknown systematic uncertainties, resulting in larger overall uncertainties in the new evaluation. Similar underestimation of uncertainties may be present in other evaluations. It could be expected that the latest evaluations have the best value, since they should contain new experimental data and use the best evaluation method. It is proposed that where there are multiple evaluations of data that disagreement between evaluations indicates that there is an underlying problem with at least one of the evaluations or the underlying experimental data. Coherence between evaluations may be taken as an indication that the data can be used with greater confidence, however it does not mean that there are no errors common to all evaluations. Comparisons between

a e-mail: alan.cresswell@glasgow.ac.uk (corresponding author) 
evaluations are relatively simple, though not previously used by practitioners using these data. However, assessing and understanding any differences is often beyond the expertise of applied users of these data.

The intention of this work is not to produce comprehensive appraisals of existing data, which would be a considerable task with the effect of creating a further evaluation. Rather, the intention is to identify radionuclides where there are inconsistencies that lead to reduced confidence in the data, in particular where these would be significant in applied fields. In these instances the issues are discusses and further investigations, which could include a new comprehensive appraisal of existing data as well as further measurements, are suggested.

This paper will concentrate on parameters used for applications where it is conventional to consider an infinite matrix of uniformly distributed natural radionuclides. In the infinite matrix condition, all decay energy (excluding that carried by neutrinos) is deposited within the matrix. Thus, the energy absorbed per decay is the sum of the product of energy and intensity for all decay paths, and it is only necessary to consider nuclear data, without consideration of other complicating factors such as radiation transport, and the review is limited in scope to natural radionuclides. The review of nuclear data presented here would be applicable to the source components of dose rate assessments in other situations where radiation transport is a factor, for example, where the source distribution is not uniform, and/or where the properties of the material receiving the dose are different from the source medium. Similar considerations would also apply to the nuclear data used for dose rate calculations from anthropogenic radionuclides. It is noted that nuclear data for anthropogenic radionuclides has been reviewed previously, in particular radionuclides used for instrumental calibration [2-5] and for medical applications [6-9].

\section{Nuclear data tables}

Nuclear data on half lives, decay energies and intensities and branching ratios has been collected for more than 100 years, and is a constantly growing resource as more measurements are conducted. With the very large quantity of data available and the specialist nature of many publications it is often impractical for practitioners in applied fields to assimilate the primary data, in particular for the natural series decay chains (for ${ }^{235} \mathrm{U},{ }^{238} \mathrm{U},{ }^{232} \mathrm{Th}$ ) with the relatively large number of nuclides that need to be considered. Therefore it is convenient to refer to evaluated libraries where the work to gather and assess the large body of primary data has already been done, though this requires confidence in the quality of the evaluations conducted. To aid in assessing the confidence practitioners may have in these evaluations, the data in three different groups of semi-independent evaluations are examined.

Early compilations of nuclear data included the Table of Radionuclides in 1940, with later editions renamed the Table of Isotopes, produced by collaborators at the Lawrence Berkeley Laboratory. The Evaluated Nuclear Structure Data File (ENSDF) was the first comprehensive nuclear structure data base, developed by staff at Oak Ridge in the 1960s. In the late 1970s, while the 7th edition of the Table of Isotopes [10] was being compiled, the different US evaluation efforts were joined together under the US Nuclear Data Network. The ENSDF consortium developed, and an international network of evaluators was established under the IAEA [11]. The ENSDF database is maintained by the US National Nuclear Data Center at Brookhaven National Laboratory [12]. The database is under constant development, with updated publication of evaluated data in Nuclear Data Sheets and Nuclear Physics A at a rate of approximately every 7-11 years. The 8th edition of the Table of Isotopes [13] was produced using ENSDF data.

The NEA and OECD coordinated evaluation projects with particular emphasis on nuclear data relevant to reactor physics, which for decay data produced two evaluated libraries, the Joint Evaluated File Version 2.2 (JEF2.2) in 1993 [14] and Joint Evaluated Fission and Fusion File Version 3.1.1 (JEFF 3.1.1) in 2007 [15]. Both of these data bases were developed with significant input from earlier ENSDF evaluations, and are fixed, without ongoing development and revision.

It has been noted that "A significant limitation of many of these sets of data is that there are no comments indicating the origin of the data for a particular radionuclide and especially what processing was done by the authors. This limitation is understandable since such documentation would require a great deal of effort and would take up a great deal of space. However, this makes it impossible for others to judge the quality of the evaluations and for subsequent evaluators to make good use of the results." [16]. This observation, along with "For almost any radionuclide one will find the related data in several compilations and the values of the quantities of interest will generally differ. Often these differences are insignificant for applied spectrometry and they can be ignored, but occasionally even small differences are important. Even if the differences are insignificant, they are a nuisance because one has to make a choice among them even though one may not have any basis for determining which is the best." [16], led to the formation the Decay Data Evaluation Project (DDEP) in 1995 [16,17]. The intention of the DDEP collaboration is to give the most precise values that are justified, with a methodology that includes accounting for all measurements of a quantity (either using or explicitly excluding each measurement), provide written documentation of all the data used and the decisions made, and for each evaluation to be reviewed by other members of the DDEP. The DDEP evaluation procedures were used in developing a Library of Recommended Actinide Decay Data $[18,19]$ by a coordinated research project of the International Atomic Energy Agency (IAEA), with the outputs of this evaluation included within the DDEP library. The majority of the DDEP outputs considered here were produced in the context of this IAEA project. 
Recommendations from the National Physical Laboratory [20] considers that "The DDEP data generally represents the best available decay data for the radionuclides which it covers", and "The data contained in ENSDF are comprehensive, accurate and traceable. NPL recommends and uses nuclear data from ENSDF where radionuclides have not yet been evaluated through the other recommended data sources." However, data from any evaluation project, regardless of endorsements, should still be critically assessed if one is to use it with confidence.

The various evaluated libraries are not entirely independent. They all derive from the same primary measurements, with the obvious exception of more recent measurements being available for more recent evaluations. In many cases, the evaluators may be the same, and the evaluation methods will be similar, with some parameters such as level spin and parity and transition multipolarities carried forward from earlier evaluations relatively uncritically. Nevertheless, it is recognised that in most cases variations in the recommended data persist between different libraries despite the dependencies between evaluations.

The purpose of this paper is to examine the different evaluated nuclear data libraries for naturally occurring radionuclides: the decay chains from ${ }^{238} \mathrm{U},{ }^{235} \mathrm{U}$ and ${ }^{232} \mathrm{Th}$, and the decays of ${ }^{40} \mathrm{~K}$ and ${ }^{87} \mathrm{Rb}$. This will identify the individual radionuclides where there is significant variability in the evaluated nuclear data, or where the uncertainties are larger, which result in the most significant reduction in confidence. This examination of differences in evaluated libraries then leads to a more extensive review of the data and evaluation approaches used for those radionuclides identified as most significant, and recommendations where further experimental data may result in greater agreement and confidence in the accuracy of the recommended data.

\section{Examination of evaluated data for naturally occurring radionuclides}

The data in the JEF2.2, JEFF3.11, ENSDF and DDEP libraries were interrogated to tabulate values for the half lives, mean decay energies and where appropriate branching ratios for all naturally occurring radionuclides in the ${ }^{238} \mathrm{U},{ }^{235} \mathrm{U}$ and ${ }^{232} \mathrm{Th}$ decay series, and ${ }^{40} \mathrm{~K}$ and ${ }^{87} \mathrm{Rb}$. The analyses here propagate the uncertainties stated in the evaluations, which are taken to be at the one sigma confidence level. Mean decay energies and uncertainties for the JEF2.2 and JEFF3.11 libraries were taken from the JANIS3.0 data browser, and for the ENSDF library using the NuDat2 tool. The DDEP evaluations do not tabulate mean decay energies, and for this library the recommended energies and intensities for all individual decays have been used to calculate the mean values and uncertainties. Where the intensity is given as a maximum value this has been included in the analysis as half the stated maximum value, with an uncertainty of half the maximum. Examination of these tabulated data indicate where different evaluations have produced significantly different values, and further examination of the data used in the evaluations can highlight the origin of these differences and options for resolving the discrepancies. Uncertainties throughout this paper are expressed at the one sigma confidence level, where recommended data report uncertainties to large numbers of significant figures these have been truncated to 1-2 significant figures.

\section{$3.1{ }^{238} \mathrm{U}$ decay series}

The half lives and decay modes with branching ratios for the ${ }^{238} \mathrm{U}$ decay series are given in table 1 . There is good consistency in all these values across the four evaluated libraries, suggesting that these values can be used with confidence. The mean decay energies for the ${ }^{238} \mathrm{U}$ decay series are given in table 2 . While in the majority of instances these are consistent across the four evaluated libraries, and thus may be used with confidence, there are some exceptions to this which warrant further examination.

\subsection{1 ${ }^{234 \mathrm{~m}} \mathrm{~Pa}$ and ${ }^{234} \mathrm{~Pa}$}

For ${ }^{234 \mathrm{~m}} \mathrm{~Pa}$, the mean gamma energy in the JEF2.2 library is significantly lower than for the other three libraries. This is driven by the intensity assigned to the $1001 \mathrm{keV}$ emission $(0.59 \pm 0.01 \%$ in JEF2.2, $0.84 \pm 0.01 \%$ in JEFF3.11 and ENSDF and $0.85 \pm 0.01 \%$ in DDEP). This emission accounts for $0.2-0.3 \%$ of the total gamma emission from the decay series, and hence is not significant for the majority of applications. This emission can be used in the detection of nuclear material as a signature for purified uranium, and the intensity would be important for quantification. The $0.59 \pm 0.01 \%$ in JEF2.2 is taken from a single measurement with scintillation detectors [21], whereas subsequent measurements using semiconductor detectors yield larger intensities between 0.79-0.92\% (reported in [22]) which result in the larger intensity reported in the later evaluations. The ENSDF and DDEP evaluations note that the energy of the isomeric state in ${ }^{234} \mathrm{~Pa}$ is poorly defined, with Q-values for the IT to the ground state given as $73.92(2)+x$ keV and for the beta decay to ${ }^{234} \mathrm{U}$ as $2269(4)+x \mathrm{keV}$. The DDEP evaluation notes that $x<10 \mathrm{keV}$. Thus, it appears that the uncertainties expressed in the evaluations for the energies of the decays from this isomeric state are probably underestimated since they do not appear to include the uncertainty in the value of $x$. 
Table 1. Half lives and decay modes for the ${ }^{238} \mathrm{U}$ decay series from the JEF2.2, JEFF3.11, ENSDF and DDEP evaluated libraries.

\begin{tabular}{|c|c|c|c|c|c|c|c|c|}
\hline \multirow{2}{*}{ Nuclide } & \multicolumn{4}{|c|}{ Half life } & \multicolumn{4}{|c|}{ Decay modes and branching ratios } \\
\hline & JEF 2.2 & JEFF3.11 & ENSDF & DDEP & JEF2.2 & JEFF3.11 & ENSDF & DDEP \\
\hline${ }^{238} \mathrm{U}$ & $4.4681 \times 10^{9} \mathrm{a}$ & $4.4680 \times 10^{9} \mathrm{a}$ & $4.4681 \times 10^{9} \mathrm{a}$ & $4.4680 \times 10^{9} \mathrm{a}$ & $\alpha$ to ${ }^{234} \mathrm{Th}$ & & & \\
\hline${ }^{234} \mathrm{Th}$ & $24.10 \mathrm{~d}$ & $24.09 \mathrm{~d}$ & $24.10 \mathrm{~d}$ & $24.10 \mathrm{~d}$ & $\beta$ to ${ }^{234 \mathrm{~m}} \mathrm{~Pa}$ & & & \\
\hline \multirow[t]{4}{*}{${ }^{234 \mathrm{~m}} \mathrm{~Pa}$} & $1.17 \mathrm{~m}$ & $1.17 \mathrm{~m}$ & $1.159 \mathrm{~m}$ & $1.159 \mathrm{~m}$ & $\beta$ to ${ }^{234} \mathrm{U}$ & $\beta$ to ${ }^{234} \mathrm{U}$ & $\beta$ to ${ }^{234} \mathrm{U}$ & $\beta$ to ${ }^{234} \mathrm{U}$ \\
\hline & & & & & $(99.87 \%)$ & $(99.85 \%)$ & $(99.84 \%)$ & $(99.85 \%)$ \\
\hline & & & & & IT to ${ }^{234} \mathrm{~Pa}$ & IT to ${ }^{234} \mathrm{~Pa}$ & IT to ${ }^{234} \mathrm{~Pa}$ & IT to ${ }^{234} \mathrm{~Pa}$ \\
\hline & & & & & $(0.13 \%)$ & $(0.15 \%)$ & $(0.16 \%)$ & $(0.15 \%)$ \\
\hline${ }^{234} \mathrm{~Pa}$ & $6.70 \mathrm{~h}$ & $6.78 \mathrm{~h}$ & $6.70 \mathrm{~h}$ & $6.70 \mathrm{~h}$ & $\beta$ to ${ }^{234} \mathrm{U}$ & & & \\
\hline${ }^{234} \mathrm{U}$ & $245705 \mathrm{a}$ & $245705 \mathrm{a}$ & $245505 \mathrm{a}$ & $245500 \mathrm{a}$ & $\alpha$ to ${ }^{230} \mathrm{Th}$ & & & \\
\hline${ }^{230} \mathrm{Th}$ & $75401.5 \mathrm{a}$ & $75401.5 \mathrm{a}$ & $75381.6 \mathrm{a}$ & - & $\alpha$ to ${ }^{226} \mathrm{Ra}$ & & & \\
\hline${ }^{226} \mathrm{Ra}$ & $1600.04 \mathrm{a}$ & $1600 \mathrm{a}$ & $1600.04 \mathrm{a}$ & $1600 \mathrm{a}$ & $\alpha$ to ${ }^{222} \mathrm{Rn}$ & & & \\
\hline${ }^{222} \mathrm{Rn}$ & $3.825 \mathrm{~d}$ & $3.8231 \mathrm{~d}$ & $3.8235 \mathrm{~d}$ & $3.8232 \mathrm{~d}$ & $\alpha$ to ${ }^{218} \mathrm{Po}$ & & & \\
\hline \multirow[t]{4}{*}{${ }^{218} \mathrm{Po}$} & $3.05 \mathrm{~m}$ & $3.098 \mathrm{~m}$ & $3.098 \mathrm{~m}$ & $3.071 \mathrm{~m}$ & $\alpha$ to ${ }^{214} \mathrm{~Pb}$ & $\alpha$ to ${ }^{214} \mathrm{~Pb}$ & $\alpha$ to ${ }^{214} \mathrm{~Pb}$ & $\alpha$ to ${ }^{214} \mathrm{~Pb}$ \\
\hline & & & & & $(99.98 \%)$ & $(99.981 \%)$ & $(99.98 \%)$ & $(99.978 \%)$ \\
\hline & & & & & $\beta$ to ${ }^{218} \mathrm{At}$ & $\beta$ to ${ }^{218} \mathrm{At}$ & $\beta$ to ${ }^{218} \mathrm{At}$ & $\beta$ to ${ }^{218} \mathrm{At}$ \\
\hline & & & & & $(0.02 \%)$ & $(0.019 \%)$ & $(0.02 \%)$ & $(0.022 \%)$ \\
\hline${ }^{214} \mathrm{~Pb}$ & $26.8 \mathrm{~m}$ & $26.8 \mathrm{~m}$ & $26.8 \mathrm{~m}$ & $26.916 \mathrm{~m}$ & $\beta$ to ${ }^{214} \mathrm{Bi}$ & & & \\
\hline \multirow[t]{4}{*}{${ }^{218} \mathrm{At}$} & $1.6 \mathrm{~s}$ & $1.5 \mathrm{~s}$ & $1.5 \mathrm{~s}$ & $1.4 \mathrm{~s}$ & $\alpha$ to ${ }^{214} \mathrm{Bi}$ & & & \\
\hline & & & & & $(99.9 \%)$ & & & \\
\hline & & & & & $\beta$ to ${ }^{214} \mathrm{Rn}$ & & & \\
\hline & & & & & $(0.1 \%)^{(a)}$ & & & \\
\hline \multirow[t]{4}{*}{${ }^{214} \mathrm{Bi}$} & $19.9 \mathrm{~m}$ & $19.9 \mathrm{~m}$ & $19.9 \mathrm{~m}$ & $19.8 \mathrm{~m}$ & $\beta$ to ${ }^{214} \mathrm{Po}$ & & & \\
\hline & & & & & $(99.979 \%)$ & & & \\
\hline & & & & & $\alpha$ to ${ }^{210} \mathrm{Tl}$ & & & \\
\hline & & & & & $(0.021 \%)^{(a)}$ & & & \\
\hline${ }^{214} \mathrm{Po}$ & $0.165 \mathrm{~ms}$ & $0.1637 \mathrm{~ms}$ & $0.1643 \mathrm{~ms}$ & $0.1623 \mathrm{~ms}$ & $\alpha$ to ${ }^{210} \mathrm{~Pb}$ & & & \\
\hline${ }^{210} \mathrm{~Pb}$ & $22.30045 \mathrm{a}$ & $22.16002 \mathrm{a}$ & $22.20047 \mathrm{a}$ & $22.23 \mathrm{a}$ & $\beta$ to ${ }^{210} \mathrm{Bi}$ & & & \\
\hline${ }^{210} \mathrm{Bi}$ & $5.013 \mathrm{~d}$ & $5.012 \mathrm{~d}$ & $5.012 \mathrm{~d}$ & $5.011 \mathrm{~d}$ & $\beta$ to ${ }^{210} \mathrm{Po}$ & & & \\
\hline${ }^{210} \mathrm{Po}$ & $138.40046 \mathrm{~d}$ & $138.38773 \mathrm{~d}$ & $138.37604 \mathrm{~d}$ & $138.3763 \mathrm{~d}$ & $\alpha$ to ${ }^{206} \mathrm{~Pb}$ & & & \\
\hline
\end{tabular}

(a) Data for very low yield branches are not tabulated here.

For ${ }^{234} \mathrm{~Pa}$, there are significant differences in the mean beta energies between the JEF2.2/JEFF3.11 evaluations and the ENSDF/DDEP evaluations. There are smaller differences in the mean gamma energies, although within the uncertainties given for the JEF2.2 and JEFF3.11 evaluations and within $3 \sigma$ for the ENSDF and DDEP evaluations. The DDEP evaluators [23] note that beta ${ }^{-}$decay scheme is based on a single measurement result [24] which includes 28 unplaced gamma rays, carrying about $3.2 \%$ of the total intensity. In addition there is inconsistency between the Q-value determined from evaluated beta ${ }^{-}$decay radiation and mass differences. Both ENSDF and DDEP evaluations include several beta transitions that are assigned maximum intensities, and the summed intensities of the other transitions exceed $100 \%$ (108.4\% for ENSDF and 102.9\% for DDEP), the intensities assigned to these transitions needs to be re-examined. The DDEP evaluators recommend further measurements to determine the decay scheme with greater precision. Since this radionuclide is a branch with $\sim 0.15 \%$ of the decays these variations are not significant for most applications. 
Table 2. Mean decay energies for the ${ }^{238} \mathrm{U}$ decay series from the JEF2.2, JEFF3.11, ENSDF and DDEP evaluated libraries.

\begin{tabular}{|c|c|c|c|c|c|c|c|c|c|c|c|c|}
\hline \multirow[t]{2}{*}{ Nuclide } & \multicolumn{4}{|c|}{ Mean $\alpha$ energy $(\mathrm{keV})$} & \multicolumn{4}{|c|}{ Mean $\beta$ energy (keV) } & \multicolumn{4}{|c|}{ Mean $\gamma$ energy $(\mathrm{keV})$} \\
\hline & JEF2.2 & JEFF3.11 & ENSDF & DDEP & JEF 2.2 & JEFF3.11 & ENSDF & DDEP & JEF2.2 & JEFF3.11 & ENSDF & DDEP \\
\hline \multirow[t]{2}{*}{${ }^{238} \mathrm{U}$} & 4190 & 4187 & 4190 & 4187 & & & & & 0.064 & 0.053 & 0.043 & 0.054 \\
\hline & \pm 240 & \pm 30 & \pm 160 & \pm 30 & & & & & \pm 0.012 & \pm 0.005 & \pm 0.004 & \pm 0.006 \\
\hline \multirow[t]{2}{*}{${ }^{234} \mathrm{Th}$} & & & & & 46.06 & 44.61 & 47.81 & 47.29 & 7.94 & 7.53 & 6.58 & 6.70 \\
\hline & & & & & \pm 1.05 & \pm 1.07 & \pm 1.43 & \pm 2.54 & \pm 0.25 & \pm 0.41 & \pm 0.36 & \pm 0.26 \\
\hline \multirow[t]{2}{*}{${ }^{234 \mathrm{~m}} \mathrm{~Pa}$} & & & & & 814.5 & 816.2 & 812.1 & 810.2 & 10.94 & 16.07 & 16.01 & 16.20 \\
\hline & & & & & \pm 2.2 & \pm 4.0 & \pm 2.7 & \pm 1.7 & \pm 0.13 & \pm 0.22 & \pm 0.09 & \pm 0.10 \\
\hline \multirow[t]{2}{*}{${ }^{234} \mathrm{~Pa}$} & & & & & 189 & 170 & 222 & 226 & 1329 & 1382 & 1423 & 1394 \\
\hline & & & & & \pm 15 & \pm 11 & \pm 23 & \pm 28 & \pm 100 & \pm 170 & \pm 30 & \pm 31 \\
\hline \multirow[t]{2}{*}{${ }^{234} \mathrm{U}$} & 4759.2 & 4759.2 & 4759.0 & 4759.4 & & & & & 0.1072 & 0.1072 & 0.1146 & 0.1136 \\
\hline & \pm 1.5 & \pm 1.5 & \pm 8.8 & \pm 1.5 & & & & & \pm 0.0012 & \pm 0.0012 & \pm 0.0062 & \pm 0.0044 \\
\hline \multirow[t]{2}{*}{${ }^{230} \mathrm{Th}$} & 4665 & 4665 & 4664 & (a) & & & & & 0.371 & 0.371 & 0.372 & (a) \\
\hline & \pm 15 & \pm 15 & \pm 15 & & & & & & \pm 0.030 & \pm 0.030 & \pm 0.022 & \\
\hline \multirow[t]{2}{*}{${ }^{226} \mathrm{Ra}$} & 4774.7 & 4773.3 & 4774.0 & 4773.2 & & & & & 6.121 & 6.598 & 6.703 & 6.639 \\
\hline & \pm 3.3 & \pm 0.2 & \pm 3.3 & \pm 184.1 & & & & & \pm 0.056 & \pm 0.021 & \pm 0.112 & \pm 0.036 \\
\hline \multirow[t]{2}{*}{${ }^{222} \mathrm{Rn}$} & 5489.3 & 5489.2 & 5489.0 & 5489.0 & & & & & 0.357 & 0.388 & 0.3876 & 0.3876 \\
\hline & \pm 1.6 & \pm 0.7 & \pm 0.6 & \pm 0.6 & & & & & \pm 0.102 & \pm 0.041 & \pm 0.0015 & \pm 0.0015 \\
\hline \multirow[t]{2}{*}{${ }^{218} \mathrm{Po}$} & 6001.34 & 6001.35 & 6001.00 & 6001.02 & 0.0141 & 0.0136 & 0.0143 & 0.0161 & 0.0092 & 0.0092 & 0.0091 & 0.0092 \\
\hline & \pm 0.61 & \pm 0.11 & \pm 0.17 & \pm 0.22 & \pm 0.0071 & \pm 0.0010 & \pm 0.0016 & \pm 0.0024 & \pm 0.0008 & \pm 0.0042 & \pm 0.0041 & \pm 0.0092 \\
\hline \multirow[t]{2}{*}{${ }^{214} \mathrm{~Pb}$} & & & & & 221.0 & 223.5 & 224.7 & 223.5 & 226.8 & 218.7 & 222.5 & 222.8 \\
\hline & & & & & \pm 3.7 & \pm 2.6 & \pm 4.7 & \pm 3.6 & \pm 7.7 & \pm 0.8 & \pm 0.4 & \pm 0.3 \\
\hline \multirow[t]{2}{*}{${ }^{218} \mathrm{At}$} & 6687 & 6679 & 6686 & 6694 & 1.09 & 1.09 & 1.10 & 1.10 & 3.85 & 8.76 & $0^{(\mathrm{c})}$ & $0^{(\mathrm{c})}$ \\
\hline & \pm 270 & \pm 166 & \pm 3 & \pm 67 & \pm 1.09 & \pm 0.33 & \pm 0.33 & \pm 1.10 & \pm 0.43 & \pm 0.38 & & \\
\hline \multirow[t]{2}{*}{${ }^{214} \mathrm{Bi}$} & 1.15 & 1.15 & 1.15 & 1.44 & 613.7 & 613.7 & 640.0 & 645.8 & 1536.9 & 1536.9 & 1474.0 & 1467.8 \\
\hline & \pm 0.05 & \pm 0.05 & \pm 0.04 & \pm 0.05 & \pm 15.5 & \pm 15.5 & \pm 3.3 & \pm 3.7 & \pm 30.3 & \pm 30.3 & \pm 1.6 & \pm 1.9 \\
\hline \multirow[t]{2}{*}{${ }^{214} \mathrm{Po}$} & 7687.00 & 7686.96 & 7687.00 & 7686.74 & & & & & 0.083 & 0.084 & 0.083 & 0.083 \\
\hline & \pm 0.09 & \pm 0.09 & \pm 0.09 & \pm 0.09 & & & & & \pm 0.005 & \pm 0.005 & \pm 0.005 & \pm 0.005 \\
\hline \multirow[t]{2}{*}{${ }^{210} \mathrm{~Pb}$} & & & & & 6.31 & 6.19 & 6.18 & 6.68 & 2.093 & 1.964 & 2.073 & 1.979 \\
\hline & & & & & \pm 1.33 & \pm 0.51 & \pm 0.52 & \pm 0.23 & \pm 0.140 & \pm 0.023 & \pm 0.074 & \pm 0.019 \\
\hline \multirow[t]{2}{*}{${ }^{210} \mathrm{Bi}$} & 0.0061 & 0.0061 & 0.0062 & 0.0039 & 387.8 & 387.7 & 389.2 & 317.0 & 0.00030 & 0.00030 & 0.00030 & 0.00031 \\
\hline & \pm 0.0003 & \pm 0.0004 & \pm 0.0006 & \pm 0.0004 & \pm 3.9 & \pm 0.3 & \pm 0.3 & \pm 3.0 & \pm 0.00004 & \pm 0.00003 & \pm 0.00003 & \pm 0.00003 \\
\hline \multirow[t]{2}{*}{${ }^{210} \mathrm{Po}$} & 5304.55 & 5304.44 & 5304.00 & 5304.32 & & & & & 0.0088 & 0.0097 & 0.0083 & 0.0099 \\
\hline & \pm 0.10 & \pm 0.07 & \pm 0.07 & \pm 0.07 & & & & & \pm 0.0008 & \pm 0.0003 & \pm 0.005 & \pm 0.003 \\
\hline \multirow[t]{2}{*}{ Total $^{(b)}$} & 42870 & 42867 & 42866 & 42870 & 2090 & 2086 & 2121 & 2051 & 1794 & 1791 & 1732 & 1726 \\
\hline & \pm 240 & \pm 33 & \pm 160 & \pm 190 & \pm 17 & \pm 16 & \pm 7 & \pm 7 & \pm 31 & \pm 30 & \pm 2 & \pm 2 \\
\hline
\end{tabular}

\footnotetext{
(a) ${ }^{230} \mathrm{Th}$ not included in the DDEP library at time of writing (ENSDF used in total).

(b) The totals include scaling to branching ratios (table 1), where appropriate.

(c) See sect 3.1.2 on absence of gamma decay data in ENSDF and DDEP.
} 
Table 3. Absolute intensities for the $609 \mathrm{keV}$ gamma ray used in the DDEP evaluation (taken from [27]).

\begin{tabular}{ccccccc}
\hline Reference & Lingeman et al. & Olson & Schötzig and Debertin & Lin and Harbottle & Morel et al. & Recommended \\
& $1969[28]$ & $1983[36]$ & $1983[37]$ & $1991[31]$ & $2004[38]$ & \\
\hline Value (\%) & $42.8 \pm 4.0$ & $45.0 \pm 0.7$ & $44.6 \pm 0.5$ & $46.1 \pm 0.5$ & $45.57 \pm 0.18$ & $45.49 \pm 0.19$ \\
\hline
\end{tabular}

\subsection{2 ${ }^{218} \mathrm{At}$}

${ }^{218}$ At decays to ${ }^{214} \mathrm{Bi}$, though neither the ENSDF or the DDEP evaluations give recommended spins and parities to the ${ }^{214} \mathrm{Bi}$ states populated. Neither do they list any of the transitions within the daughter from the $103 \mathrm{keV}(\sim 6.4 \%)$ or $63.7 \mathrm{keV}(\sim 90 \%)$ levels. The decay of these levels must result in production of radiation. Thus, it may be concluded that gamma and conversion electron emissions should be given in the evaluated libraries, however current data provide little information to support the assignment of intensities to any of these de-excitation paths. The DDEP and ENSDF evaluators note that there are no gamma rays observed, with the DDEP evaluator [25] commenting that deficiencies in Q-values suggest a weak gamma transition from the $62 \mathrm{keV}{ }^{214} \mathrm{Bi}$ level to the ground state. Again, this radionuclide is a $\sim 0.02 \%$ branch, and so this has no significant impact for most applications.

\subsection{3 ${ }^{214} \mathrm{Bi}$}

For ${ }^{214} \mathrm{Bi}$, there are significant differences for both beta and gamma mean energies between the evaluated libraries, with differences in excess of twice the uncertainties given by the JEF2.2 and JEFF3.11 libraries, and much more significant relative to the smaller uncertainties in the ENSDF and DDEP libraries. These differences account for approximately $1.5 \%$ of the total beta and $3.5 \%$ of the total gamma energies, and hence are significant in dose rate calculations. There are also small differences in alpha energies, with the DDEP evaluation larger by $0.3 \mathrm{MeV}$. These differences arise from the inclusion of "long range alpha decays" (very low intensity but high energy decays from excited states in ${ }^{214} \mathrm{Po}$ ) in the DDEP evaluation, whereas the other evaluations appear to only consider the alpha decays to ${ }^{210} \mathrm{Tl}$. This low intensity branch has no significance for most applications.

The beta decay from ${ }^{214} \mathrm{Bi}$ to ${ }^{214} \mathrm{Po}$ populates approximately 65 levels in the daughter nucleus, with transitions between these levels resulting in a large number of gamma emissions. The end-point energies, shapes and intensities of beta decays to these excited levels are determined from analysis of the gamma ray emission spectra. Thus differences in the evaluation of the gamma emission data will account for differences in both the gamma and beta energies. The evaluation of the gamma decay scheme involves normalising available gamma spectrometry data to the $609 \mathrm{keV}$ (1st excited state to ground state) transition, to allow the generation of a relative intensity level scheme. This is then normalised to an evaluated absolute intensity for the $609 \mathrm{keV}$ transition. The DDEP evaluation also determines the absolute gamma emission intensities for ${ }^{214} \mathrm{~Pb}$ by normalising relative efficiencies to the $609 \mathrm{keV}$ transition associated with ${ }^{214} \mathrm{Bi}[26]$.

The DDEP evaluation [27] uses gamma spectrometry data from 15 cited sources (from 1969 through 2007 ) to produce an evaluated decay scheme with intensities relative to the $609.32 \mathrm{keV}$ emission. Some additional data sets were excluded because they were either all from a single laboratory (the most recent data set from that group was used), three sets included insufficient information on the experimental methods, and one was an earlier data set which had been renormalized. Five cited references included data suitable to determine the absolute emission intensity for the $609 \mathrm{keV}$, these intensities with the evaluated recommended intensity are given in table 3 . This allows the generation of a recommended value for this emission intensity and by extension for all 212 gamma emissions included in the evaluation. The absolute intensity for the $609 \mathrm{keV}$ emission in the ENSDF libraries is identical $(45.49 \pm 0.16 \%)$, and it is concluded is probably derived from the same references. The intensity in the JEF2.2/JEFF3.11 evaluation is $46.9 \pm 4.0 \%$, and is derived from three reported values (Lingeman et al. 1969 [28] was used by DDEP, Hachem 1975 [29] was used by DDEP for relative intensities only, Cline et al. 1972 [30] is not referenced by DDEP), the Lin and Harbottle 1991 [31] data was published shortly prior to the conclusion of the JEF2.2 evaluation and may not have been available when ${ }^{214} \mathrm{Bi}$ data were evaluated, and this evaluation was not revised for the JEFF3.11 library. The 1977 Nuclear Data Sheet evaluation [32] also gives an intensity for this transition of $46.9 \%$ which it is noted derives from measurements of $I_{\beta}$ from ${ }^{214} \mathrm{~Pb}$ to ${ }^{214} \mathrm{Bi}$ ground state of $6.3 \pm 2.0 \%$ [33] leading to $I_{\gamma}$ for the $609 \mathrm{keV}$ of $46.1 \pm 1.2 \%$, and direct measurement of $47.5 \pm 1.9 \%$ [34]. The 1995 evaluation [35] giving $46.1 \pm 0.5 \%$ from Lin and Harbottle 1991 [31], with the Lingeman et al. 1969 [28], Olson 1983 [36] and Schötzig and Debertin 1983 [37] values cited but not used in the calculation of the absolute intensity. This value is larger than all the individual values used in the DDEP evaluation. The difference in this absolute intensity (3.5\%) is sufficient to explain the majority of the discrepancy in mean gamma and beta energies between the JEF2.2/JEFF3.11 evaluation and the ENSDF and DDEP evaluations. 
The critical measurement for the determination of both gamma and beta intensities for ${ }^{214} \mathrm{Bi}$ decay is the absolute intensity for the $609 \mathrm{keV}$ gamma ray. These require a source of known activity, detectors of known efficiency and a method to account for coincidence summing. For the studies included in the DDEP evaluation, Lingeman et al. 1969 [28] used sources of ${ }^{214} \mathrm{~Pb}$ and ${ }^{214} \mathrm{Bi}$ from solidified ${ }^{222} \mathrm{Rn}$, the other studies all used ${ }^{226} \mathrm{Ra}$ sources. Olson 1983 [36] used an NBS standard solution certified to $0.5 \%$ uncertainty, with two historic pitchblende sources calibrated to $0.4-0.5 \%$ uncertainty. Schötzig and Debertin 1983 [37] used alpha-foil Ra salt sources prepared more than 10 years prior to the experiment, with activities calibrated relative to standard sources in glass cylinders with corrections for absorption applied, with an overall $0.8 \%$ uncertainty in activity. Lin and Harbottle 1991 [31] used radium solution dispensed to filter paper sealed in a lucite disc and sealed for 6 weeks, checked for radon leakage and calibrated relative to a certified NBS radium source. Morel et al. 2004 [38] used two sources prepared by the D.I. Mendeleyev Institute for Metrology (VNIIM), with the source material sandwiched between two thin stainless steel sheets, which were characterised to activity uncertainties of $0.2 \%$.

For these studies measurements were mostly conducted on multiple detector systems with several multi-nuclide reference sources to calibrate the energy efficiency. Lingeman et al. 1969 [28] used two Ge(Li) detectors, of $20 \mathrm{~cm}^{3}$ and $30 \mathrm{~cm}^{3}$ volume, and IAEA multi-nuclide reference materials. Olson 1983 [36] used three Ge(Li) detectors and NBS mixed gamma-ray standards and single nuclide sources. Schötzig and Debertin 1983 [37] used two Ge(Li) detectors, of $40 \mathrm{~cm}^{3}$ and $60 \mathrm{~cm}^{3}$ volume, and a $10 \mathrm{~cm}^{3}$ planar HPGe detector, with many single multi-gamma-ray sources prepared and standardised in their laboratory. Lin and Harbottle 1991 [31] used a single $43 \%$ relative efficiency intrinsic Ge detector, calibrated with Amersham and NIST standard solutions. Morel et al. 2004 [38] used three detectors at VNIIM; a $15 \%$ relative efficiency Ge(Li) detector, a $30 \%$ relative efficiency coaxial HPGe detector, and a $40 \mathrm{~cm}^{3} \mathrm{HPGe}$ detector; with three different geometries used for each detector and calibrated to 12 different reference point sources, with further measurements at LNHB used a $100 \mathrm{~cm}^{3}$ HPGe detector in two geometries, calibrated using 11 different reference point sources.

To date, the Morel et al. 2004 [38] dataset is the most precise measurement of the critical 609 keV absolute intensity, and the relative intensities of the other emissions from the ${ }^{214} \mathrm{~Pb}$ and ${ }^{214} \mathrm{Bi}$ decays. To tie down this critical intensity more conclusively there would be value in independent measurements with similar attention to detail to rule out potential bias in the source activity certification, detector efficiencies and cascade summing corrections.

\subsection{4 ${ }^{210} \mathrm{Bi}$}

For ${ }^{210} \mathrm{Bi}$, the mean beta energy in the DDEP library is significantly lower than that in the other three libraries, with a difference more than 20 times the uncertainties that accounts for approximately $3 \%$ of the total beta energy. The DDEP evaluators [39] note that the LOGFT program was used to calculate the log $f t=8.0$ value assuming an allowed transition, whereas the average beta energy was calculated for a first forbidden transition using experimentally determined shape factors [40] and the BetaShape program [41]. The ENSDF evaluators [42] determine the same log $f t$ value and endpoint energy, but use the shape factor of [43]. This decay from the $1^{-}$ground state of ${ }^{210} \mathrm{Bi}$ to the $0^{+}$ground state of ${ }^{210} \mathrm{Po}$ is a first forbidden non-unique transition. With the calculation of beta spectra for nonunique transitions being far more difficult than for unique transitions a generalisation calculating forbidden non-unique transitions as unique transitions is often made without theoretical justification. Mougeot 2015 [44] calculates the mean energy for the unique transition as $388.66 \mathrm{keV}$, which is very similar to the ENSDF and JEFF evaluated mean energy. This suggests that these evaluations used this common generalisation, and the measured shape factor used by DDEP may be preferable. However, the calculation of $\log f t$ assuming an allowed transition, by both DDEP and ENSDF evaluators, is still questionable. Also further measurements of the shape of the beta spectrum may be warranted, since there is currently only a single measurement of this.

\section{$3.2{ }^{235} \mathrm{U}$ decay series}

The half lives and decay modes with branching ratios for the ${ }^{235} \mathrm{U}$ decay series are given in table 4 . There is good consistency in all these values across the four evaluated libraries. The mean decay energies for the ${ }^{235} \mathrm{U}$ decay series are given in table 5. These mean energies are largely consistent across the different libraries considered. The half lives and decay energies and intensities for all the radionuclides in the ${ }^{235} \mathrm{U}$ series show no significant variation across the different evaluations, and in addition the DDEP evaluators for these radionuclides do not report any issues with inconsistencies or incomplete decay schemes. This suggests that these values may be used with more confidence.

\section{$3.3^{232}$ Th decay series}

The half lives and decay modes with branching ratios for the ${ }^{232} \mathrm{Th}$ decay series are given in table 6 . There is good consistency in all these values across the four evaluated libraries, suggesting that these values can be used with confidence. The mean decay energies for the ${ }^{232} \mathrm{Th}$ decay series are given in table 7 . While in the majority of instances these are consistent across the four evaluated libraries, and thus may be used with confidence, there are some exceptions to this which warrant further examination. 
Table 4. Half lives and decay modes for the ${ }^{235} \mathrm{U}$ decay series from the JEF2.2, JEFF3.11, ENSDF and DDEP evaluated libraries.

\begin{tabular}{|c|c|c|c|c|c|c|c|c|}
\hline \multirow[t]{2}{*}{ Nuclide } & \multicolumn{4}{|c|}{ Half life } & \multicolumn{4}{|c|}{ Decay modes and branching ratios } \\
\hline & JEF2.2 & JEFF3.11 & ENSDF & DDEP & JEF2.2 & JEFF3.11 & ENSDF & DDEP \\
\hline${ }^{235} \mathrm{U}$ & $703.814 \times 10^{6} \mathrm{a}$ & $703.814 \times 10^{6} \mathrm{a}$ & $703.814 \times 10^{6} \mathrm{a}$ & $704 \times 10^{6} \mathrm{a}$ & $\alpha$ to ${ }^{231} \mathrm{Th}$ & & & \\
\hline${ }^{231} \mathrm{Th}$ & $1.06333 \mathrm{~d}$ & $1.06333 \mathrm{~d}$ & $1.06333 \mathrm{~d}$ & $1.06342 \mathrm{~d}$ & $\beta$ to ${ }^{231} \mathrm{~Pa}$ & & & \\
\hline${ }^{231} \mathrm{~Pa}$ & $32760.8 \mathrm{a}$ & $32760.8 \mathrm{a}$ & $32760.8 \mathrm{a}$ & $32760 \mathrm{a}$ & $\alpha$ to ${ }^{227} \mathrm{Ac}$ & & & \\
\hline${ }^{227} \mathrm{Ac}$ & $21.77347 \mathrm{a}$ & $21.77348 \mathrm{a}$ & $21.77247 \mathrm{a}$ & $21.772 \mathrm{a}$ & $\begin{array}{l}\beta \text { to }{ }^{227} \mathrm{Th} \\
(98.62 \%) \\
\alpha \text { to }{ }^{223} \mathrm{Fr} \\
(1.38 \%)\end{array}$ & & & \\
\hline${ }^{227} \mathrm{Th}$ & $18.71806 \mathrm{~d}$ & $18.71806 \mathrm{~d}$ & $18.68 \mathrm{~d}$ & - & $\alpha$ to ${ }^{223} \mathrm{Ra}$ & & & \\
\hline${ }^{223} \mathrm{Fr}$ & $21.8 \mathrm{~m}$ & $21.8 \mathrm{~m}$ & $22 \mathrm{~m}$ & $22 \mathrm{~m}$ & $\begin{array}{l}\beta \text { to }{ }^{223} \mathrm{Ra} \\
(99.994 \%) \\
\alpha \text { to }{ }^{219} \mathrm{At} \\
(0.006 \%)^{(\mathrm{a})}\end{array}$ & $\begin{array}{l}\beta \text { to }{ }^{223} \mathrm{Ra} \\
(99.994 \%) \\
\alpha \text { to }{ }^{219} \mathrm{At} \\
(0.006 \%)^{(\mathrm{a})}\end{array}$ & $\begin{array}{l}\beta \text { to }{ }^{223} \mathrm{Ra} \\
(99.994 \%) \\
\alpha \text { to }{ }^{219} \mathrm{At} \\
(0.006 \%)^{(\mathrm{a})}\end{array}$ & $\begin{array}{l}\beta \text { to }{ }^{223} \mathrm{Ra} \\
(99.998 \%) \\
\alpha \text { to }{ }^{219} \mathrm{At} \\
(0.002 \%)^{(\mathrm{a})}\end{array}$ \\
\hline${ }^{223} \mathrm{Ra}$ & $11.43 \mathrm{~d}$ & $11.43 \mathrm{~d}$ & $11.43 \mathrm{~d}$ & $11.43 \mathrm{~d}$ & $\alpha$ to ${ }^{219} \mathrm{Rn}$ & & & \\
\hline${ }^{219} \mathrm{Rn}$ & $3.96 \mathrm{~s}$ & $3.96 \mathrm{~s}$ & $3.96 \mathrm{~s}$ & $3.89 \mathrm{~s}$ & $\alpha$ to ${ }^{215} \mathrm{Po}$ & & & \\
\hline${ }^{215} \mathrm{Po}$ & $1.78 \mathrm{~ms}$ & $1.78 \mathrm{~ms}$ & $1.781 \mathrm{~ms}$ & $1.781 \mathrm{~ms}$ & $\begin{array}{l}\alpha \text { to }{ }^{211} \mathrm{~Pb} \\
(99.9996 \%) \\
\beta \text { to }{ }^{215} \mathrm{At} \\
(0.0004 \%)^{(\mathrm{a})}\end{array}$ & $\begin{array}{l}\alpha \text { to }{ }^{211} \mathrm{~Pb} \\
(99.9996 \%) \\
\beta \text { to }{ }^{215} \mathrm{At} \\
(0.0004 \%)^{(\mathrm{a})}\end{array}$ & $\begin{array}{l}\alpha \text { to }{ }^{211} \mathrm{~Pb} \\
(99.9998 \%) \\
\beta \text { to }{ }^{215} \mathrm{At} \\
(0.0002 \%)^{(\mathrm{a})}\end{array}$ & $\begin{array}{l}\alpha \text { to }{ }^{211} \mathrm{~Pb} \\
(99.9998 \%) \\
\beta \text { to }{ }^{215} \mathrm{At} \\
(0.0002 \%)^{(\mathrm{a})}\end{array}$ \\
\hline${ }^{211} \mathrm{~Pb}$ & $36.1 \mathrm{~m}$ & $36.1 \mathrm{~m}$ & $36.1 \mathrm{~m}$ & $36.1 \mathrm{~m}$ & $\beta$ to ${ }^{211} \mathrm{Bi}$ & & & \\
\hline${ }^{211} \mathrm{Bi}$ & $2.17 \mathrm{~m}$ & $2.17 \mathrm{~m}$ & $2.14 \mathrm{~m}$ & $2.15 \mathrm{~m}$ & $\begin{array}{l}\alpha \text { to }{ }^{207} \mathrm{Tl} \\
(99.727 \%) \\
\beta \text { to }{ }^{211} \mathrm{Po} \\
(0.273 \%)\end{array}$ & $\begin{array}{l}\alpha \text { to }{ }^{207} \mathrm{Tl} \\
(99.727 \%) \\
\beta \text { to }{ }^{211} \mathrm{Po} \\
(0.273 \%)\end{array}$ & $\begin{array}{l}\alpha \text { to }{ }^{207} \mathrm{Tl} \\
(99.724 \%) \\
\beta \text { to }{ }^{211} \mathrm{Po} \\
(0.276 \%)\end{array}$ & $\begin{array}{l}\alpha \text { to }{ }^{207} \mathrm{Tl} \\
(99.724 \%) \\
\beta \text { to }{ }^{211} \mathrm{Po} \\
(0.276 \%)\end{array}$ \\
\hline${ }^{207} \mathrm{Tl}$ & $4.77 \mathrm{~m}$ & $4.77 \mathrm{~m}$ & $4.77 \mathrm{~m}$ & $4.774 \mathrm{~m}$ & $\beta$ to ${ }^{207} \mathrm{~Pb}$ & & & \\
\hline${ }^{211} \mathrm{Po}$ & $516 \mathrm{~ms}$ & $516 \mathrm{~ms}$ & $516 \mathrm{~ms}$ & $516 \mathrm{~ms}$ & $\alpha$ to ${ }^{207} \mathrm{~Pb}$ & & & \\
\hline
\end{tabular}

(a) Data for very low yield branches are not tabulated here.

\subsection{1 ${ }^{228} \mathrm{Ra}$}

For ${ }^{228} \mathrm{Ra}$, the mean gamma energies show significant variation. The DDEP and ENSDF values are both much larger than the JEF2.2/JEFF3.11 values, slightly in excess of the larger uncertainties on the earlier evaluations, and the DDEP value is small than the ENSDF value with the difference more than one sigma. Although it is noted that these mean gamma energies are all $<0.4 \mathrm{keV}$ and have no significant influence for most applications. The DDEP evaluator [45] notes that only one paper [46] reports gamma ray energies, and only two reported lines have associated intensities. These were used to calculate emission probabilities for three other gamma rays, with a further three observed transitions not included in the decay scheme.

The DDEP evaluation reviews beta intensities, but does not report mean energies for these transitions, noting that the ENSDF assigned intensities result in negative gamma emission probabilities. For this work, the DDEP intensities have been matched with the ENSDF mean energies to calculate a mean beta energy for the DDEP data. The DDEP evaluator also notes that the evaluated half life is based on three measurements, the most recent in 1962.

\subsection{2 ${ }^{228} \mathrm{AC}$}

For ${ }^{228} \mathrm{Ac}$, the mean gamma energy from the JEF2.2/JEFF3.11 libraries are much larger than given in the ENSDF and DDEP libraries, although these are consistent within the large uncertainties of the earlier evaluations these differences are 9 times the smaller uncertainties from the ENSDF and DDEP libraries. The DDEP evaluation [47] 
Table 5. Mean decay energies for the ${ }^{235} \mathrm{U}$ decay series from the JEF2.2, JEFF3.11, ENSDF and DDEP evaluated libraries.

\begin{tabular}{|c|c|c|c|c|c|c|c|c|c|c|c|c|}
\hline \multirow[t]{2}{*}{ Nuclide } & \multicolumn{4}{|c|}{ Mean $\alpha$ energy (keV) } & \multicolumn{4}{|c|}{ Mean $\beta$ energy (keV) } & \multicolumn{4}{|c|}{ Mean $\gamma$ energy $(\mathrm{keV})$} \\
\hline & JEF 2.2 & JEFF3.11 & ENSDF & DDEP & JEF 2.2 & JEFF3.11 & ENSDF & DDEP & JEF2.2 & JEFF3.11 & ENSDF & DDEP \\
\hline \multirow[t]{2}{*}{${ }^{235} \mathrm{U}$} & 4387 & 4389 & 4339 & 4391 & & & & & 149.5 & 148.6 & 148.6 & 148.55 \\
\hline & & & \pm 165 & \pm 15 & & & & & & & \pm 1.4 & \pm 0.60 \\
\hline \multirow[t]{2}{*}{${ }^{231} \mathrm{Th}$} & & & & & 77 & 77 & 79 & 78 & 13.16 & 13.16 & 13.13 & 13.12 \\
\hline & & & & & & & \pm 21 & \pm 21 & & & \pm 0.42 & \pm 0.19 \\
\hline \multirow[t]{2}{*}{${ }^{231} \mathrm{~Pa}$} & 4974 & 4974 & 4924 & 4985 & & & & & 31.46 & 31.46 & 33.24 & 31.50 \\
\hline & & & \pm 13 & \pm 115 & & & & & & & \pm 1.17 & \pm 0.98 \\
\hline \multirow[t]{2}{*}{${ }^{227} \mathrm{Ac}$} & 68.11 & 68.11 & 70.26 & 71.27 & 9.8 & 9.8 & 9.8 & & 0.1752 & 0.1752 & 0.0861 & 0.0816 \\
\hline & & & \pm 1.40 & \pm 1.38 & & & \pm 0.7 & & & & \pm 0.0037 & \pm 0.0015 \\
\hline \multirow[t]{2}{*}{${ }^{227} \mathrm{Th}$} & 5911 & 5901 & 5901 & (a) & & & & & 99.3 & 108.5 & 154.3 & (a) \\
\hline & & & \pm 97 & & & & & & & & \pm 4.8 & \\
\hline \multirow[t]{2}{*}{${ }^{223} \mathrm{Fr}$} & 0.32 & 0.32 & 0.3277 & 1.06 & 339 & 339 & 346 & 355 & 48.9 & 48.9 & 47.3 & 45.8 \\
\hline & & & \pm 0.0018 & \pm 0.23 & & & \pm 26 & \pm 53 & & & \pm 4.6 & \pm 4.1 \\
\hline \multirow[t]{2}{*}{${ }^{223} \mathrm{Ra}$} & 5678 & 5678 & 5665 & 5711 & & & & & 86.30 & 86.30 & 89.33 & 90.87 \\
\hline & & & \pm 833 & \pm 111 & & & & & & & \pm 1.06 & \pm 0.98 \\
\hline \multirow[t]{2}{*}{${ }^{219} \mathrm{Rn}$} & 6759 & 6759 & 6755 & 6756 & & & & & 53.65 & 53.65 & 56.58 & 57.98 \\
\hline & & & \pm 88 & \pm 73 & & & & & & & \pm 2.43 & \pm 1.07 \\
\hline \multirow[t]{2}{*}{${ }^{215} \mathrm{Po}$} & 7385.9 & 7385.9 & 7388.0 & 7385.8 & 0.0009 & 0.0009 & & & 0.21 & 0.21 & 0.30 & 0.25 \\
\hline & & & \pm 2.2 & \pm 2.2 & & & & & & & \pm 0.09 & \pm 0.08 \\
\hline \multirow[t]{2}{*}{${ }^{211} \mathrm{~Pb}$} & & & & & 444.7826 & 444.7826 & 445.5 & 445.8 & 66.82 & 66.82 & 63.09 & 63.12 \\
\hline & & & & & & & \pm 2.3 & \pm 2.3 & & & \pm 0.62 & \pm 0.60 \\
\hline \multirow[t]{2}{*}{${ }^{211} \mathrm{Bi}$} & 6548.7 & 6548.7 & 6549.0 & 6548.3 & 0.481 & 0.481 & 0.477 & 0.477 & 45.51 & 45.51 & 45.71 & 45.63 \\
\hline & & & \pm 12.8 & \pm 21.0 & & & \pm 0.009 & \pm 0.009 & & & \pm 0.40 & \pm 0.67 \\
\hline \multirow[t]{2}{*}{${ }^{207} \mathrm{Tl}$} & & & & & 491.3 & 491.3 & 491.6 & 491.2 & 2.18 & 2.18 & 2.38 & 2.38 \\
\hline & & & & & & & \pm 2.1 & \pm 2.1 & & & \pm 0.08 & \pm 0.08 \\
\hline \multirow[t]{2}{*}{${ }^{211} \mathrm{Po}$} & 7442.2 & 7442.2 & 7442.0 & 7442.6 & & & & & 7.7317 & 7.7317 & 8.01 & 7.60 \\
\hline & & & \pm 1.9 & \pm 2.0 & & & & & & & \pm 0.24 & \pm 0.13 \\
\hline \multirow[t]{2}{*}{ Total $^{(b)}$} & 41650 & 41642 & 41530 & 41688 & 1027 & 1027 & 1030 & 1028 & 548 & 556 & 605 & 606 \\
\hline & & & \pm 226 & \pm 202 & & & \pm 21 & \pm 21 & & & \pm 6 & \pm 5 \\
\hline
\end{tabular}

(a) ${ }^{227} \mathrm{Th}$ not included in the DDEP library at time of writing (ENSDF used in total).

(b) The totals include scaling to branching ratios (table 4 ), where appropriate.

notes that this decay scheme is incomplete, with the effective Q-value calculated from individual decay rates and intensities $(2010 \pm 100 \mathrm{keV})$ low compared to the Q-value from mass differences $(2123.8 \pm 2.7 \mathrm{keV})$. There is a $\sim 7 \%$ discrepancy between beta and gamma emissions, suggesting missing gammas. "Further measurements of the gamma data, particularly at low energy, would be of benefit, as would coincidence studies to validate the placement of gammas in the level scheme" [47]. Absolute gamma emissions were normalised to the $463 \mathrm{keV}$ emission, however it is noted that "this value is not consistent with expected beta decay characteristics" [47].

\subsection{3 ${ }^{220} \mathrm{Rn}$ and ${ }^{216} \mathrm{Po}$}

Although there are no differences between the different evaluations for ${ }^{220} \mathrm{Rn}$ and ${ }^{216} \mathrm{Po}$, the DDEP evaluator $[48,49]$ notes that the alpha decay energies and intensities are derived from gamma spectrometry measurements. Although these are internally consistent, it is recommended that alpha particle studies are needed to confirm the validity of the proposed decay schemes. 
Table 6. Half lives and decay modes for the ${ }^{232}$ Th decay series from the JEF2.2, JEFF3.11, ENSDF and DDEP evaluated libraries.

\begin{tabular}{|c|c|c|c|c|c|c|c|c|}
\hline \multirow[t]{2}{*}{ Nuclide } & \multicolumn{4}{|c|}{ Half life } & \multicolumn{4}{|c|}{ Decay modes and branching ratios } \\
\hline & JEF2.2 & JEFF3.11 & ENSDF & DDEP & JEF2.2 & JEFF3.11 & ENSDF & DDEP \\
\hline${ }^{232} \mathrm{Th}$ & $1.40503 \times 10^{10} \mathrm{a}$ & $1.40503 \times 10^{10} \mathrm{a}$ & $1.40503 \times 10^{10} \mathrm{a}$ & $1.402 \times 10^{10} \mathrm{a}$ & $\alpha$ to ${ }^{228} \mathrm{Ra}$ & & & \\
\hline${ }^{228} \mathrm{Ra}$ & $5.75012 \mathrm{a}$ & $5.75012 \mathrm{a}$ & $5.75012 \mathrm{a}$ & $5.75 \mathrm{a}$ & $\beta$ to ${ }^{228} \mathrm{Ac}$ & & & \\
\hline${ }^{228} \mathrm{Ac}$ & $6.15 \mathrm{~h}$ & $6.15 \mathrm{~h}$ & $6.15 \mathrm{~h}$ & $6.15 \mathrm{~h}$ & $\beta$ to ${ }^{228} \mathrm{Th}$ & & & \\
\hline${ }^{228} \mathrm{Th}$ & $1.91304 \mathrm{a}$ & $1.9127 \mathrm{a}$ & $1.91204 \mathrm{a}$ & $1.9126 \mathrm{a}$ & $\alpha$ to ${ }^{224} \mathrm{Ra}$ & & & \\
\hline${ }^{224} \mathrm{Ra}$ & $3.62 \mathrm{~d}$ & $3.64 \mathrm{~d}$ & $3.66 \mathrm{~d}$ & $3.631 \mathrm{~d}$ & $\alpha$ to ${ }^{220} \mathrm{Rn}$ & & & \\
\hline${ }^{220} \mathrm{Rn}$ & $55.6 \mathrm{~s}$ & $55.8 \mathrm{~s}$ & $55.6 \mathrm{~s}$ & $55.8 \mathrm{~s}$ & $\alpha$ to ${ }^{216} \mathrm{Po}$ & & & \\
\hline${ }^{216} \mathrm{Po}$ & $145 \mathrm{~ms}$ & $150 \mathrm{~ms}$ & $145 \mathrm{~ms}$ & $148 \mathrm{~ms}$ & $\alpha$ to ${ }^{212} \mathrm{~Pb}$ & & & \\
\hline${ }^{212} \mathrm{~Pb}$ & $10.64 \mathrm{~h}$ & $10.64 \mathrm{~h}$ & $10.64 \mathrm{~h}$ & $10.64 \mathrm{~h}$ & $\beta$ to ${ }^{212} \mathrm{Bi}$ & & & \\
\hline${ }^{212} \mathrm{Bi}$ & $1.00917 \mathrm{~h}$ & $1.009 \mathrm{~h}$ & $1.00917 \mathrm{~h}$ & $1.009 \mathrm{~h}$ & $\begin{array}{l}\alpha \text { to }{ }^{208} \mathrm{Tl} \\
(35.9386 \%) \\
\beta \text { to }{ }^{212} \mathrm{Po} \\
(64.0474 \%) \\
\beta \alpha \text { to }{ }^{208} \mathrm{~Pb} \\
(0.0140 \%)\end{array}$ & $\begin{array}{l}\alpha \text { to }{ }^{208} \mathrm{Tl} \\
(35.93 \%) \\
\beta \text { to }{ }^{212} \mathrm{Po} \\
(64.056 \%) \\
\beta \alpha \text { to }{ }^{208} \mathrm{~Pb} \\
(0.014 \%)\end{array}$ & $\begin{array}{l}\alpha \text { to }{ }^{208} \mathrm{Tl} \\
(35.94 \%) \\
\beta \text { to }{ }^{212} \mathrm{Po} \\
(64.06 \%)\end{array}$ & $\begin{array}{l}\alpha \text { to }{ }^{208} \mathrm{Tl} \\
(35.93 \%) \\
\beta \text { to }{ }^{212} \mathrm{Po} \\
(64.07 \%)\end{array}$ \\
\hline${ }^{208} \mathrm{Tl}$ & $3.055 \mathrm{~m}$ & $3.053 \mathrm{~m}$ & $3.053 \mathrm{~m}$ & $3.058 \mathrm{~m}$ & $\beta$ to ${ }^{208} \mathrm{~Pb}$ & & & \\
\hline${ }^{212} \mathrm{Po}$ & $0.300 \mu \mathrm{s}$ & $0.298 \mu \mathrm{s}$ & $0.299 \mu \mathrm{s}$ & $0.300 \mu \mathrm{s}$ & $\alpha$ to ${ }^{208} \mathrm{~Pb}$ & & & \\
\hline
\end{tabular}

Table 7. Mean decay energies for the ${ }^{232}$ Th decay series from the JEF2.2, JEFF3.11, ENSDF and DDEP evaluated libraries.

\begin{tabular}{|c|c|c|c|c|c|c|c|c|c|c|c|c|}
\hline \multirow[t]{2}{*}{ Nuclide } & \multicolumn{4}{|c|}{ Mean $\alpha$ energy $(\mathrm{keV})$} & \multicolumn{4}{|c|}{ Mean $\beta$ energy (keV) } & \multicolumn{4}{|c|}{ Mean $\gamma$ energy $(\mathrm{keV})$} \\
\hline & JEF2.2 & JEFF3.11 & ENSDF & DDEP & JEF 2.2 & JEFF3.11 & ENSDF & DDEP & JEF 2.2 & JEFF3.11 & ENSDF & DDEP \\
\hline \multirow[t]{2}{*}{${ }^{232} \mathrm{Th}$} & 4010 & 4010 & 3997 & 3997 & & & & & 0.145 & 0.145 & 0.197 & 0.195 \\
\hline & \pm 170 & \pm 170 & \pm 73 & \pm 73 & & & & & \pm 0.033 & \pm 0.033 & \pm 0.010 & \pm 0.013 \\
\hline \multirow[t]{2}{*}{${ }^{228} \mathrm{Ra}$} & & & & & 7.6 & 7.6 & 7.2 & 7.6 & 0.158 & 0.158 & 0.369 & 0.292 \\
\hline & & & & & \pm 1.3 & \pm 1.3 & \pm 0.7 & $\pm 1.5^{(\mathrm{a})}$ & \pm 0.152 & \pm 0.152 & \pm 0.028 & \pm 0.020 \\
\hline \multirow[t]{2}{*}{${ }^{228} \mathrm{Ac}$} & & & & & 373.4 & 373.4 & 354.5 & 354.4 & 956 & 956 & 864 & 864 \\
\hline & & & & & \pm 44.6 & \pm 44.6 & \pm 35.3 & \pm 35.3 & \pm 134 & \pm 134 & \pm 10 & \pm 10 \\
\hline \multirow[t]{2}{*}{${ }^{228} \mathrm{Th}$} & 5398 & 5401 & 5404 & 5403 & & & & & 1.986 & 1.833 & 1.962 & 1.909 \\
\hline & \pm 69 & \pm 15 & \pm 80 & \pm 38 & & & & & \pm 0.030 & \pm 0.089 & \pm 0.018 & \pm 0.027 \\
\hline \multirow[t]{2}{*}{${ }^{224} \mathrm{Ra}$} & 5673.3 & 5672.8 & 5673.0 & 5672.8 & & & & & 9.64 & 10.00 & 9.96 & 10.00 \\
\hline & \pm 3.2 & \pm 5.5 & \pm 3.2 & \pm 3.9 & & & & & \pm 0.12 & \pm 0.10 & \pm 0.12 & \pm 0.10 \\
\hline \multirow[t]{2}{*}{${ }^{220} \mathrm{Rn}$} & 6287.59 & 6287.59 & 6287.00 & 6287.58 & & & & & 0.693 & 0.627 & 0.6267 & 0.632 \\
\hline & \pm 1.03 & \pm 1.37 & \pm 1.45 & \pm 1.28 & & & & & \pm 0.066 & \pm 0.088 & \pm 0.0001 & \pm 0.083 \\
\hline \multirow[t]{2}{*}{${ }^{216} \mathrm{Po}$} & 6778.5 & 6778.6 & 6778.0 & 6778.4 & & & & & 0.0145 & 0.0153 & 0.0153 & 0.0153 \\
\hline & \pm 0.5 & \pm 0.5 & \pm 0.5 & \pm 0.5 & & & & & \pm 0.0024 & \pm 0.0024 & \pm 0.0024 & \pm 0.0024 \\
\hline \multirow[t]{2}{*}{${ }^{212} \mathrm{~Pb}$} & & & & & 101.3 & 100.7 & 100.2 & 101.3 & 114.7 & 114.5 & 114.8 & 115.1 \\
\hline & & & & & \pm 4.4 & \pm 3.1 & \pm 3.2 & \pm 2.2 & \pm 0.7 & \pm 1.0 & \pm 1.3 & \pm 1.3 \\
\hline \multirow[t]{2}{*}{${ }^{212} \mathrm{Bi}$} & 2176.5 & 2175.1 & 2175.0 & 2174.0 & 488.7 & 491.4 & 493.9 & 493.7 & 105.8 & 104.6 & 102.9 & 103.9 \\
\hline & \pm 7.1 & \pm 9.1 & \pm 5.2 & \pm 8.9 & \pm 2.4 & \pm 2.2 & \pm 1.2 & \pm 0.9 & \pm 1.3 & \pm 1.3 & \pm 1.2 & \pm 0.9 \\
\hline \multirow[t]{2}{*}{${ }^{208} \mathrm{Tl}$} & & & & & 556 & 554 & 560 & 559 & 3378 & 3379 & 3375 & 3374 \\
\hline & & & & & \pm 14 & \pm 5 & \pm 5 & \pm 5 & \pm 12 & \pm 6 & \pm 2 & \pm 2 \\
\hline \multirow[t]{2}{*}{${ }^{212} \mathrm{Po}$} & 8784.60 & 8785.06 & 8785.00 & 8785.17 & & & & & & & & \\
\hline & \pm 8.79 & \pm 0.01 & \pm 0.12 & \pm 0.11 & & & & & & & & \\
\hline \multirow[t]{2}{*}{$\operatorname{Total}^{(\mathrm{b})}$} & 35950 & 35950 & 35940 & 35941 & 1171 & 1172 & 1157 & 1158 & 2403 & 2402 & 2308 & 2308 \\
\hline & \pm 180 & \pm 170 & \pm 110 & \pm 83 & \pm 45 & \pm 45 & \pm 35 & \pm 35 & \pm 134 & \pm 134 & \pm 10 & \pm 10 \\
\hline
\end{tabular}

(a) ${ }^{228}$ Ra mean $\beta$ not included in the DDEP library at time of writing (calculated using ENSDF mean energies and DDEP intensities).

(b) The totals include scaling to branching ratios (table 6), where appropriate. 
Table 8. Half lives and decay modes for ${ }^{40} \mathrm{~K}$ and ${ }^{87} \mathrm{Rb}$ from the JEF2.2, JEFF3.11, ENSDF and DDEP evaluated libraries.

\begin{tabular}{|c|c|c|c|c|c|c|c|c|}
\hline \multirow[t]{2}{*}{ Nuclide } & \multicolumn{4}{|c|}{ Half life $\left(\times 10^{9} \mathrm{a}\right)$} & \multicolumn{4}{|c|}{ Decay modes and branching ratios } \\
\hline & JEF 2.2 & JEFF3.11 & ENSDF & DDEP & JEF 2.2 & JEFF3.11 & ENSDF & DDEP \\
\hline \multirow[t]{10}{*}{${ }^{40} \mathrm{~K}$} & 1.280 & 1.265 & 1.248 & 1.250 & $\beta$ to ${ }^{40} \mathrm{Ca}$ & $\beta$ to ${ }^{40} \mathrm{Ca}$ & $\beta$ to ${ }^{40} \mathrm{Ca}$ & $\beta$ to ${ }^{40} \mathrm{Ca}$ \\
\hline & \pm 0.010 & \pm 0.020 & \pm 0.003 & \pm 0.003 & & & & \\
\hline & & & & & $(89.3 \pm 0.1 \%)$ & $(89.14 \pm 0.13 \%)$ & $(89.14 \pm 0.18 \%)$ & $(89.25 \pm 0.17 \%)$ \\
\hline & & & & & $\mathrm{EC} / \beta^{+}$to ${ }^{40} \mathrm{Ar}$ & $\mathrm{EC} / \beta^{+}$to ${ }^{40} \mathrm{Ar}$ & $\mathrm{EC}$ to ${ }^{40} \mathrm{Ar} 2^{+}$ & EC to ${ }^{40} \mathrm{Ar} 2^{+}$ \\
\hline & & & & & $(10.7 \pm 0.1 \%)$ & $(10.86 \pm 0.13 \%)$ & $(10.66 \pm 0.13 \%)$ & $(10.55 \pm 0.11 \%)$ \\
\hline & & & & & & & EC to ${ }^{40} \mathrm{Ar}$ gs & EC to ${ }^{40} \mathrm{Ar}$ gs \\
\hline & & & & & & & $(0.20 \pm 0.10 \%)$ & $(0.20 \pm 0.10 \%)$ \\
\hline & & & & & & & $\beta^{+}$to ${ }^{40} \mathrm{Ar}$ gs & $\beta^{+}$to ${ }^{40} \mathrm{Ar}$ gs \\
\hline & & & & & & & $(0.00100$ & $(0.00100$ \\
\hline & & & & & & & $\pm 0.00013 \%)$ & $\pm 0.00012 \%)$ \\
\hline \multirow[t]{2}{*}{${ }^{87} \mathrm{Rb}$} & 47.97 & 48.10 & 48.10 & (a) & $\beta$ to ${ }^{87} \mathrm{Sr}$ & & & \\
\hline & \pm 1.30 & \pm 0.90 & \pm 0.90 & & & & & \\
\hline
\end{tabular}

(a) ${ }^{87} \mathrm{Rb}$ not included in the DDEP library at time of writing.

Table 9. Mean decay energies for ${ }^{40} \mathrm{~K}$ and ${ }^{87} \mathrm{Rb}$ from the JEF2.2, JEFF3.11, ENSDF and DDEP evaluated libraries.

\begin{tabular}{|c|c|c|c|c|c|c|c|c|}
\hline \multirow[t]{2}{*}{ Nuclide } & \multicolumn{4}{|c|}{ Mean $\beta$ energy $(\mathrm{keV})$} & \multicolumn{4}{|c|}{ Mean $\gamma$ energy $(\mathrm{keV})$} \\
\hline & JEF 2.2 & JEFF3.11 & ENSDF & DDEP & JEF 2.2 & JEFF3.11 & ENSDF & DDEP \\
\hline${ }^{40} \mathrm{~K}$ & $521.5 \pm 0.6$ & $453.2 \pm 0.7$ & $499.3 \pm 1.0$ & $453.7 \pm 0.9$ & $156.3 \pm 1.5$ & $155.7 \pm 1.9$ & $155.8 \pm 2.7$ & $154.1 \pm 1.6$ \\
\hline${ }^{87} \mathrm{Rb}$ & $78.8 \pm 0.7$ & $81.7 \pm 0.7$ & $81.7 \pm 0.7$ & (a) & & & & \\
\hline
\end{tabular}

(a) ${ }^{87} \mathrm{Rb}$ not included in the DDEP library at time of writing.

\section{$3.4{ }^{40} \mathrm{~K}$ and ${ }^{87} \mathrm{Rb}$}

Potassium and rubidium are often associated in minerals, and thus it is conventional to combine the beta dose rates from both for assumed relative composition. The half lives and decay modes for these radionuclides are given in table 8 , with the mean decay energies in table 9.

For ${ }^{40} \mathrm{~K}$ the half lives given in the evaluated libraries considered here carry relatively large uncertainties, of $1.0-1.5 \%$ for the JEF2.2 and JEFF3.11 libraries, and 0.2\% for the ENSDF and DDEP libraries. In addition, the half lives vary significantly with the JEF2.2 value approximately $2.5 \%$ larger than that given in the ENSDF and DDEP libraries. This difference in half life is significant for the calculation of many derived parameters when ${ }^{40} \mathrm{~K}$ activity is given in terms of elemental composition $(\% \mathrm{~K})$, and also for geochronology applications based on ${ }^{40} \mathrm{~K}$ decay. There is also considerable variation in the mean beta energies reported in each library, ranging from $\sim 450 \mathrm{keV}$ to $\sim 520 \mathrm{keV}$. This variation could introduce $5-10 \%$ errors in applications needing the energy production, such as dose rate measurements and geothermal heat production.

\subsection{1 ${ }^{40} \mathrm{~K}$ half life}

The half lives listed in table 8 range from 1.25 to $1.28 \times 10^{9}$ a, a variation in excess of $2 \%$. with uncertainties of $\sim 0.25 \%$ for the most recent evaluations (ENSDF and DDEP). The DDEP and ENSDF values are consistent within stated uncertainties, as are the JEF2.2 and JEFF 3.11 values which have much larger uncertainties. However, the JEF2.2 value is inconsistent with the ENSDF and DDEP values, and the JEFF3.11 value is only consistent because of the large uncertainty ascribed to it.

${ }^{40} \mathrm{~K}$ decays by competing paths, beta ${ }^{-}$decay to ${ }^{40} \mathrm{Ca}$ and electron capture and beta ${ }^{+}$decay to ${ }^{40}$ Ar. The total half life is determined directly or from measurements of the partial half life for each of these paths, and the associated branching ratios (see sect. 3.4.3 below). The DDEP evaluators [50] consider 14 measurements of the partial half life for the electron capture decay to the excited ${ }^{40} \mathrm{Ar}$ state (measured from the de-excitation gamma ray at $1460.8 \mathrm{keV}$ ), 19 measurements of the partial half life for the beta ${ }^{-}$decay to ${ }^{40} \mathrm{Ca}$, and 6 total half life measurements. After recalculating the partial half lives with the appropriate branching ratio, the total half lives used in the DDEP evaluation are shown in fig. 1. It is noted that all but one of these measurements were conducted in the 1970s or earlier. The exception [51] was conducted specifically in response to a call for improved decay constants for geochronology, with measurements conducted to high precision using liquid scintillation counting of multiple samples of $\mathrm{KCl}$ and $\mathrm{KNO}_{3}$ solutions. 


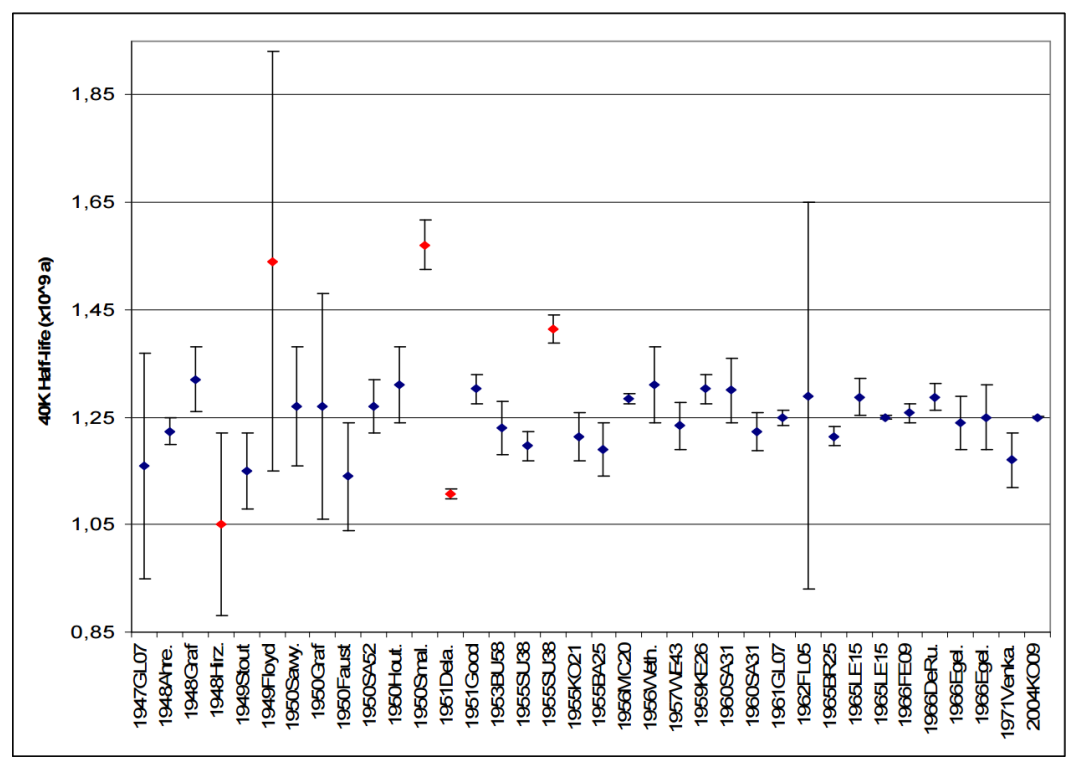

Fig. 1. ${ }^{40} \mathrm{~K}$ half lives used for DDEP evaluation (taken from [49]). Red points were excluded from the evaluation.

Measurements of the half life also require the natural abundance of ${ }^{40} \mathrm{~K}$. The data used for the DDEP and ENSDF evaluations are based on a natural abundance of $0.011672 \pm 0.000041 \%$ [52], generally accepted as the most accurate measurement, with some earlier reported values adjusted to use this abundance. Recent more precise measurements of $0.011668 \pm 0.000008 \%$ [53] are consistent with this, but are too recent to have been included in the evaluations. The value recommended by the International Union of Pure and Applied Chemistry [54] of 0.00117 $\pm 0.0001 \%$ increases the uncertainties in table 8 by a factor of four, and the use of this value would account for much of the increased uncertainties in the JEF2.2 and JEFF3.11 evaluations.

In geochronology based on the decay of ${ }^{40} \mathrm{~K}$ it is desirable to know the ${ }^{40} \mathrm{~K}$ to the greatest possible precision. Given the importance of the ${ }^{40} \mathrm{~K}$ decay constants in these communities, independent evaluations of the half life and branching ratios have been conducted combining experimental nuclear physics data with Ar-Ar ages from independently dated minerals. Min et al. 2000 [55] reviewed nuclear data giving an evaluated half life of $1.255 \pm 0.025 \times 10^{9}$ a, and comparisons between $\mathrm{Ar}-\mathrm{Ar}$ and $\mathrm{U}-\mathrm{Pb}$ dating giving a half life of $1.29 \times 10^{9} \mathrm{a}$. Combining these produces a half life of $1.269 \pm 0.025 \times$ $10^{9} \mathrm{a}$, with a beta ${ }^{-}$decay branching ratio of $0.894 \pm 0.019$. Renne et al. 2010 [56] conducted a much larger comparison of Ar-Ar with U-Pb dates and produced a half life of $1.2479 \pm 0.0024 \times 10^{9} \mathrm{a}$, consistent with the ENSDF and DDEP values, with a slightly reduced uncertainty.

\subsubsection{Mean beta $^{-}$decay energy}

Values for the mean beta $^{-}$decay energy also vary significantly between different evaluated libraries. This value is a function of the beta end point energy, the shape of the beta spectrum and the branching ratio for the beta- ${ }^{-}$decay $^{-}$ ${ }^{40} \mathrm{Ca}$. These values are given in table 10 . The end point of the beta ${ }^{-}$decay energy spectrum is consistent across all evaluated libraries, with only small variations in the branching ratios. The major difference to the mean energy is the shape of the beta ${ }^{-}$decay spectrum assumed, which significantly varies the mean energy per beta ${ }^{-}$decay. $^{-}$

To determine the mean beta decay energy, it is necessary to know the shape and end-point energy of the beta spectrum. The shape of the beta spectrum is proportional to a factor $p W q^{2}$ for sharing momentum between the leptons, the Fermi function $F(Z, W)$ and a shape factor $C(W)$ :

$$
\frac{\mathrm{d} N}{\mathrm{~d} W} \propto p W q^{2} F(Z, W) C(W),
$$

where $W$ is the total beta energy, $Z$ is the atomic number of the daughter, $p$ is the momentum of the beta particle and $q$ the momentum of the neutrino.

Theoretical shape factors for allowed or forbidden unique transitions are given by

$$
C(W)=(2 L-1) ! \sum_{k=1}^{L} \lambda_{k} \frac{p^{2(k-1)} q^{2(L-k)}}{(2 k-1) ![2(L-k)+1] !},
$$

where $L=\Delta J$, and $L=1$ for $\Delta J=0$. The parameter $\lambda_{k}$ cannot be calculated in a straightforward manner, and typically an assumption that $\lambda_{k}=1$ is used. 
Table 10. ${ }^{40} \mathrm{~K}_{\text {beta }}{ }^{-}$decay energies in different evaluated libraries.

\begin{tabular}{llllll}
\hline Library & Date & $\begin{array}{l}\text { End point } \\
(\mathrm{keV})\end{array}$ & $\begin{array}{l}\text { Mean energy per beta decay } \\
(\mathrm{keV})\end{array}$ & Branching ratio & $\begin{array}{l}\text { Mean energy per }{ }^{40} \mathrm{~K} \text { decay } \\
(\mathrm{keV})\end{array}$ \\
\hline JEF2.2 & 1993 & $1311.6 \pm 0.5$ & $584.9 \pm 0.6$ & $0.893 \pm 0.001$ & $521.48 \pm 0.62$ \\
JEFF3.11 & 2007 & $1311.04 \pm 0.12$ & $508.29 \pm 0.05$ & $0.8915 \pm 0.0013$ & $453.16 \pm 0.66$ \\
ENSDF & 2004 & $1311.07 \pm 0.12$ & $560.18 \pm 0.05$ & $0.8914 \pm 0.0018$ & $499.3 \pm 1.0$ \\
& 2017 & $1311.07 \pm 0.12$ & $560.18 \pm 0.05$ & $0.8928 \pm 0.0013$ & $500.1 \pm 1.0$ \\
DDEP & 2009 & $1311.07 \pm 0.12$ & $508.32 \pm 0.05$ & $0.8925 \pm 0.0017$ & $453.68 \pm 0.87$ \\
\hline
\end{tabular}

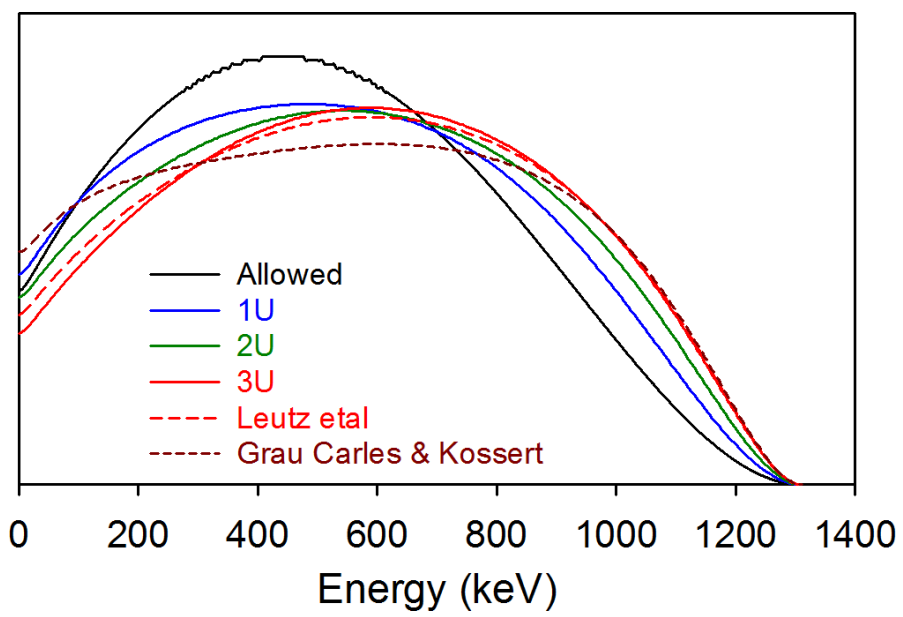

Fig. 2. Beta spectra calculated by the BetaShape program [44,58] using theoretical shape factors, with the $\lambda_{k}=1$ assumption, for allowed and first, second and third unique forbidden transitions, and for experimentally derived shape factors reported by Leutz et al. 1965 [57] and Grau Carles and Kossert 2007 [59]. All spectra are calculated using an endpoint energy of 1311.07 keV.

Table 11. Mean beta energies calculated for an endpoint energy of $1311.07 \mathrm{keV}$ using the BetaShape program [44,58] for theoretical shape factors, assuming $\lambda_{k}=1$, and experimentally measured shape factors. With mean energies from the LOGFT program for comparison.

\begin{tabular}{cccc}
\hline & $\mathrm{C}(\mathrm{W})$ & \multicolumn{2}{c}{ Mean beta energy (keV) } \\
& & BetaShape & LOGFT \\
\hline Allowed & 1 & $507.83 \pm 0.05$ & $508.31 \pm 0.05$ \\
$1 \mathrm{U}$ & $p^{2}+q^{2}$ & $536.08 \pm 0.05$ & $534.04 \pm 0.05$ \\
$2 \mathrm{U}$ & $p^{4}+q^{4}+\frac{10}{3} p^{2} q^{2}$ & $563.01 \pm 0.05$ & $560.18 \pm 0.05$ \\
$3 \mathrm{U}$ & $p^{6}+q^{6}+7 p^{2} q^{2}\left(p^{2}+q^{2}\right)$ & $587.89 \pm 0.05$ & \\
Grau Carles and Kossert (2007) & $0.95 p^{6}+1.05 q^{6}+6.3 p^{2} q^{4}+6.25 q^{2} p^{4}$ & $583.98 \pm 0.05$ & \\
\hline
\end{tabular}

The decay from ${ }^{40} \mathrm{~K}$ (ground state $4^{-}$) to ${ }^{40} \mathrm{Ca}$ (ground state $0^{+}$) is a third forbidden unique transition. The commonly used LOGFT program for calculating the shape of the spectrum only calculates allowed and first and second unique forbidden transitions, and defaults to the parameters for an allowed transition if any other transition type is input. This program was used by the evaluators for both the ENSDF and DDEP libraries.

Recalculations of the beta spectral shapes to evaluate the reliability of the $\lambda_{k}=1$ approximation [44] have included the ${ }^{40} \mathrm{~K}$ beta spectrum using an experimental shape factor from Leutz et al. 1965 [57]. The program BetaShape [41, 44,58] has been used to generate spectra for different shape factors (fig. 2), theoretically with the $\lambda_{k}=1$ assumption and for experimental shape factors reported in the literature. The mean beta energies have been calculated for these, and given in table 11 with corresponding mean energies from LOGFT for the allowed and first and second unique forbidden transitions. The mean energy for the Leutz et al. 1965 [57] shape factor is identical to that reported by Mougeot 2015 [44]. Recent high precision measurements of beta spectra have been conducted [59], proposing a shape factor of the form $C(W)=\lambda_{1} p^{6}+\lambda_{2} q^{6}+7 p^{2} q^{2}\left(p^{2}+q^{2}\right)$ for ${ }^{40} \mathrm{~K}$, with $\lambda_{1}=1.8$ and $\lambda_{2}=1.23$, to resolve discrepancies between cutoff energy yield and maximum point energy. However, the authors note that this form of shape factor fails Cherenkov counting tests. 
Table 12. ${ }^{40} \mathrm{~K}$ decay probability ratios and probabilities from the ENSDF and DDEP evaluations.

\begin{tabular}{|c|c|c|c|}
\hline Ratio & ENSDF (2004) & DDEP & Comment \\
\hline $\mathrm{P}_{\mathrm{EC}, 1460}: \mathrm{P}_{\beta^{-}}$ & $0.1195 \pm 0.0014$ & $0.1182 \pm 0.0012$ & $\begin{array}{l}\text { Ratio of partial half lives, determined from intensities } \\
\text { of the } 1460 \mathrm{keV} \text { gamma and } \text { beta }^{-} \text {decay }\end{array}$ \\
\hline $\mathrm{P}_{\beta^{+}}: \mathrm{P}_{\beta^{-}}$ & $(1.12 \pm 0.14) \times 10^{-5}$ & $(1.12 \pm 0.14) \times 10^{-5}$ & $\begin{array}{l}\beta^{+} \text {is a very difficult measurement due to low intensity } \\
\text { and pair production from } 1460 \mathrm{keV} \text { gamma. }\end{array}$ \\
\hline $\mathrm{P}_{\mathrm{EC}, \mathrm{gs}}: \mathrm{P}_{\beta+}$ & $200 \pm 100$ & $200 \pm 100$ & $\begin{array}{l}\text { Calculated theoretically. } \\
\text { Note that the } 2017 \text { ENSDF evaluation sets this to zero }\end{array}$ \\
\hline \multicolumn{4}{|l|}{ Probability } \\
\hline $\mathrm{P}_{\beta^{-}}$ & $89.14 \pm 0.13 \%$ & $89.25 \pm 0.17 \%$ & \\
\hline $\mathrm{P}_{\mathrm{EC}, 1460}$ & $10.66 \pm 0.13 \%$ & $10.55 \pm 0.11 \%$ & This corresponds to the $1460 \mathrm{keV}$ gamma intensity. \\
\hline $\mathrm{P}_{\mathrm{EC}, \mathrm{gs}}$ & $0.20 \pm 0.10 \%$ & $0.20 \pm 0.10 \%$ & Note that the 2017 ENSDF evaluation sets this to zero \\
\hline $\mathrm{P}_{\beta+}$ & $0.00100 \pm 0.00013 \%$ & $0.00100 \pm 0.00012 \%$ & \\
\hline
\end{tabular}

When allowed to default to the allowed transition the LOGFT program generates a mean energy of $560.18 \mathrm{keV}$, when forced to the $2 \mathrm{U}$ transition it generates $508.32 \mathrm{keV}$. The mean energy per decay (table 10) suggests that the JEFF3.11 and DDEP evaluations forced LOGFT to the 2U transition, whereas the ENSDF evaluations allowed LOGFT to default to the allowed transition. The DDEP evaluators [50] state that the mean energy is given by the LOGFT program, without further elaboration. The mean energy calculated from the BetaShape program for the theoretical 3U shape factor and the experimentally measured shape factor of Leutz et al. 1965 [57] are significantly larger than the mean energies calculated by LOGFT and used in the ENSDF and DDEP evaluations. The mean energy used in the older JEF2.2 evaluation, and the value of $583 \mathrm{keV}$ given in the 7 th edition of Table of Isotopes [10] is consistent with these $3 \mathrm{U}$ shape factors. This suggests that in the case of ${ }^{40} \mathrm{~K}$ evaluations would have been more accurate if the earlier experimental shape measurements were used, rather than the use of a program incapable of calculating the correct shape.

\subsubsection{Branching ratios}

The final parameter for the estimation of the mean beta ${ }^{-}$decay energy per ${ }^{40} \mathrm{~K}$ decay is the branching ratio for the beta $^{-}$decay route. The decay of ${ }^{40} \mathrm{~K}$ follows four possible decays, each with a corresponding probability. The probability of electron capture to the excited state of ${ }^{40} \mathrm{Ar}$ also determines the gamma energy per decay. For geochronology based on decay of ${ }^{40} \mathrm{~K}$ the total probability of decay to ${ }^{40} \mathrm{Ar}$ is needed, and in addition the probability of beta ${ }^{+}$decay is important since this mode would include recoil effects that may affect argon retention:

- $\mathrm{Beta}^{-}$decay to the ground state of ${ }^{40} \mathrm{Ca}\left(\mathrm{P}_{\beta^{-}}\right)$;

- Electron capture to the $1460.8 \mathrm{keV} 2^{+}$level of ${ }^{40} \mathrm{Ar}\left(\mathrm{P}_{\mathrm{EC}, 1460}\right)$;

- Electron capture to the $0^{+}$ground state of ${ }^{40} \mathrm{Ar}\left(\mathrm{P}_{\mathrm{EC}, \mathrm{gs}}\right)$;

- Beta $^{+}$decay to the $0^{+}$ground state of ${ }^{40} \mathrm{Ar}\left(\mathrm{P}_{\beta_{+}}\right)$.

Ratios of the probability for each path are determined (table 12), from which the probability for each decay path can be calculated. The difficulties in measuring $\beta^{+}$decays results in experimental data being limited to maximum values for the $\mathrm{P}_{\beta^{+}}: \mathrm{P}_{\beta^{-}}$ratio.

The 2004 ENSDF evaluation [60] includes a beta ${ }^{+}$decay branch to the ${ }^{40} \mathrm{Ar}$ ground state, this transition is excluded in the 2017 evaluation [61] resulting in a slight increase in the branching ratio for the beta ${ }^{-}$decay to ${ }^{40} \mathrm{Ca}$, without any elaboration on the reason for this within the published evaluation. For the earlier ENSDF evaluation, and the DDEP evaluation, this path was calculated based on a theoretical calculation of the $\mathrm{P}_{\mathrm{EC}, \mathrm{gs}}$ : $\mathrm{P}_{\beta+}$ ratio, which can be calculated for $1 \mathrm{U}$ and $2 \mathrm{U}$ transitions using LOGFT, with an assumption made for the value for $3 \mathrm{U}$ transitions. This is described in the documentation for the DDEP evaluation, "The $\mathrm{P}_{\mathrm{ec}, \mathrm{gs}} / \mathrm{P}_{\beta}+$ ratio was calculated theoretically by Helmer, as described hereafter. The LOGFT program cannot calculate this ratio for this unique 3rd forbidden (3U) transition. But it can calculate the theoretical value for $1 \mathrm{U}$ and $2 \mathrm{U}$ transitions. For the former $(1 \mathrm{U})$, this ratio is 8.51 (9) and for the latter (2U), it is 45.20 (47). Making the assumption that the $3 \mathrm{U}$ ratio rises by the same factor (45.20/8.51), then $\mathrm{P}_{\mathrm{ec}, \mathrm{gs}} / \mathrm{P}_{\beta^{+}}=240$. Following Helmer's choice, a value of 200 (100) for $\mathrm{P}_{\mathrm{ec}, \mathrm{gs}} / \mathrm{P}_{\beta^{+}}$was adopted in the present calculation." [50]. A calculation of this ratio for the $3 \mathrm{U}$ transitions would remove this assumption. 
Table 13. Dose rate conversion factors for an infinite matrix reported in recent literature [62-64], and from this work. The beta conversion factor using the mean ${ }^{40} \mathrm{~K}$ decay energy from the experimental shape factor of Leutz et al. (1965) [57] is included.

\begin{tabular}{|c|c|c|c|c|c|c|c|c|}
\hline \multirow[t]{2}{*}{ Source } & \multicolumn{3}{|c|}{${ }^{235+238} \mathrm{U}\left(\mathrm{mGy} \mathrm{a}^{-1} \mathrm{ppm}^{-1}\right)$} & \multicolumn{3}{|c|}{${ }^{232} \mathrm{Th}\left(\mathrm{mGy} \mathrm{a}^{-1} \mathrm{ppm}^{-1}\right)$} & \multicolumn{2}{|c|}{${ }^{40} \mathrm{~K}+{ }^{87} \mathrm{Rb}\left(\mathrm{mGy} \mathrm{a}^{-1} \%^{-1}\right)^{(\mathrm{a})}$} \\
\hline & Alpha & Beta & Gamma & Alpha & Beta & Gamma & Beta & Gamma \\
\hline $\begin{array}{l}\text { Adamiec and Aitken } \\
\text { (1998) [62] }\end{array}$ & 2.780 & 0.1460 & 0.1130 & 0.732 & 0.0273 & 0.0476 & 0.8023 & 0.2433 \\
\hline $\begin{array}{l}\text { Guerin et al. } \\
(2011) \text { [63] }\end{array}$ & 2.795 & 0.1457 & 0.1116 & 0.738 & 0.0277 & 0.0479 & 0.8167 & 0.2491 \\
\hline Liritzis et al. & 2.793 & 0.1459 & 0.1118 & 0.738 & 0.0275 & 0.0481 & 0.8196 & 0.2498 \\
\hline (2013) [64] & \pm 0.011 & \pm 0.0004 & \pm 0.0002 & \pm 0.003 & \pm 0.0009 & \pm 0.0002 & \pm 0.0073 & \pm 0.0048 \\
\hline \multirow[t]{2}{*}{ JEF2.2 } & 2.795 & 0.1446 & 0.1157 & 0.737 & 0.0279 & 0.0502 & 0.8329 & 0.2443 \\
\hline & \pm 0.025 & \pm 0.0011 & \pm 0.0021 & \pm 0.005 & \pm 0.0009 & \pm 0.0028 & \pm 0.0097 & \pm 0.0036 \\
\hline \multirow[t]{2}{*}{ JEFF3.11 } & 2.795 & 0.1442 & 0.1155 & 0.737 & 0.0278 & 0.0502 & 0.7352 & 0.2463 \\
\hline & \pm 0.012 & \pm 0.0011 & \pm 0.0019 & \pm 0.005 & \pm 0.0009 & \pm 0.0028 & \pm 0.0131 & \pm 0.0053 \\
\hline \multirow[t]{2}{*}{ ENSDF } & 2.794 & 0.1464 & 0.1117 & 0.737 & 0.0279 & 0.0483 & 0.8193 & 0.2497 \\
\hline & \pm 0.019 & \pm 0.0024 & \pm 0.0010 & \pm 0.004 & \pm 0.0007 & \pm 0.0003 & \pm 0.0075 & \pm 0.0048 \\
\hline \multirow[t]{2}{*}{ DDEP } & 2.793 & 0.1461 & 0.1115 & 0.739 & 0.0279 & 0.0484 & 0.7458 & 0.2470 \\
\hline & \pm 0.019 & \pm 0.0024 & \pm 0.0009 & \pm 0.005 & \pm 0.0009 & \pm 0.0003 & \pm 0.0069 & \pm 0.0034 \\
\hline \multirow[t]{2}{*}{ Leutz et al. (1965) } & & & & & & & 0.854 & \\
\hline & & & & & & & \pm 0.008 & \\
\hline
\end{tabular}

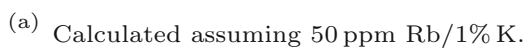

The parameter $\log f t$ is used to determine the partial half life for a given beta decay or electron capture transition. The Fermi integral $f\left(Z_{d}, Q\right)$ is a function of the atomic number of the daughter $\left(Z_{d}\right)$ and the transition $\mathrm{Q}$ value, and is readily calculated and tabulated. The comparative half life is the product of the Fermi integral and the half life of the decay path (in seconds), $f t$, which spans many orders of magnitude and is conventionally expressed as the common logarithm, $\log f t$. Values for $\log f t$ fall into groups that correlate to spin and parity change in the decay, and calculated values can be used to determine partial half lives and branching ratios.

The DDEP evaluators [50] state that the $\log f t$ value $(20.58 \pm 0.01)$ for the beta ${ }^{-}$decay transition to the ground state of ${ }^{40} \mathrm{Ca}$ was estimated from the $\log f t$ values for the $1 \mathrm{U}$ and $2 \mathrm{U}$ transitions, with the assumption that the value for the $3 \mathrm{U}$ transition increases by the same proportion. This follows the same assumptions as that used for the decay probabilities for the EC and beta ${ }^{+}$decay transitions to the ${ }^{40} \mathrm{Ar}$ ground state described above. For the ENSDF evaluation, the $\log f t$ value $(20.75)$ is "from private communication from R.B. Firestone" [60,61].

\section{Impact on derived parameters}

The nuclear data reviewed here is used to derive parameters applied to other disciplines. Two examples of the parameters are given here, conversion factors for calculating dose rates in an infinite matrix and for calculating geological heat production rates. Both sets of parameters are determined for an infinite matrix, thus removing the need to consider radiation transport and other factors in the calculations. Values are presented for these derived from the evaluated libraries examined in this work and reported in the literature, and the impact of the differences between evaluations noted.

\subsection{Dose rate conversion parameters}

Table 13 lists the dose rate conversion parameters calculated in this work for the JEF2.2, JEFF3.11, ENSDF and DDEP libraries, along with a conversion parameter using the mean beta energy for ${ }^{40} \mathrm{~K}$ calculated for the experimental shape factor of Leutz et al. 1965 [57]. For comparison, three commonly used literature values are also included. Note that these literature values all derive from earlier versions of the ENSDF library. 
Table 14. Heat production constants calculated by Birch (1954) [65] and Rybach (1976) [66], and calculated in this work for data from the JEFF3.11, ENSDF and DDEP libraries, and for ${ }^{40} \mathrm{~K}$ using the mean beta energy from the Leutz et al. (1965) [57] experimental shape factor.

\begin{tabular}{|c|c|c|c|c|c|c|}
\hline \multirow[t]{2}{*}{ Decay series/element } & \multicolumn{6}{|c|}{ Heat production $\left(\mathrm{W} \mathrm{kg}^{-1}\right)$} \\
\hline & Birch (1954) & Rybach (1976) & JEFF 3.11 & ENSDF & DDEP & Leutz et al. (1965) \\
\hline \multirow[t]{2}{*}{${ }^{238} \mathrm{U}$} & $9.41 \times 10^{-5}$ & $9.17 \times 10^{-5}$ & $(9.500 \pm 0.009)$ & $(9.508 \pm 0.012)$ & $(9.493 \pm 0.012)$ & \\
\hline & & & $\times 10^{-5}$ & $\times 10^{-5}$ & $\times 10^{-5}$ & \\
\hline \multirow[t]{2}{*}{${ }^{235} \mathrm{U}$} & $5.70 \times 10^{-4}$ & $5.75 \times 10^{-4}$ & $(5.674 \pm 0.008)$ & $(5.675 \pm 0.011)$ & $(5.675 \pm 0.011)$ & \\
\hline & & & $\times 10^{-4}$ & $\times 10^{-4}$ & $\times 10^{-4}$ & \\
\hline \multirow[t]{2}{*}{ U (natural) } & $9.68 \times 10^{-5}$ & $9.52 \times 10^{-5}$ & $(9.835 \pm 0.010)$ & $(9.843 \pm 0.011)$ & $(9.828 \pm 0.012)$ & \\
\hline & & & $\times 10^{-5}$ & $\times 10^{-5}$ & $\times 10^{-5}$ & \\
\hline \multirow[t]{2}{*}{${ }^{232} \mathrm{Th}$} & $2.65 \times 10^{-5}$ & $2.56 \times 10^{-5}$ & $(2.649 \pm 0.013)$ & $(2.652 \pm 0.012)$ & $(2.652 \pm 0.012)$ & \\
\hline & & & $\times 10^{-5}$ & $\times 10^{-5}$ & $\times 10^{-5}$ & \\
\hline \multirow[t]{2}{*}{$\mathrm{K}$ (natural) } & $3.58 \times 10^{-9}$ & $3.48 \times 10^{-9}$ & $(2.981 \pm 0.048)$ & $(3.251 \pm 0.016)$ & $(3.011 \pm 0.012)$ & $(3.345 \pm 0.012)$ \\
\hline & & & $\times 10^{-9}$ & $\times 10^{-9}$ & $\times 10^{-9}$ & $\times 10^{-9}$ \\
\hline
\end{tabular}

It can be seen that in most cases there is no significant difference in dose rate conversion parameters between the different libraries and literature values. For the uranium series, the use of the Morel et al. (2004) [38] ${ }^{214} \mathrm{Bi}$ data in the ENSDF and DDEP evaluations slightly increases the beta conversion parameter, and decreases the gamma conversion parameter, to values consistent with the recent literature values (which used the ENSDF library). For the Th series, the larger gamma decay energy for ${ }^{228} \mathrm{Ac}$ used by the JEF2.2/JEFF3.11 evaluators is evident. For K+Rb, the variation in ${ }^{40} \mathrm{~K}$ half life values is reflected in the scatter in the gamma conversion parameters, though this is still within $2 \sigma$. More significantly, the choice of shape factor for the ${ }^{40} \mathrm{~K}$ beta decay has a very substantial effect, with the parameter for the Leutz et al. (1965) [57] shape factor 4\% larger than for the 2U shape factor used in the ENSDF evaluation, and $15 \%$ larger than the allowed shape factor used in the DDEP evaluation.

\subsection{Geothermal heat production}

To assess heat production in rocks, used for assessing geothermal potential, the nuclear recoil energy also needs to be considered. In practice, this has been calculated from the atomic mass difference between the parent nuclide and the stable daughter at the end of the decay chain, less the mass of alpha particles released and the energy carried by neutrinos $[65,66]$, with the mean neutrino energy taken as $2 / 3$ the beta endpoint energy.

The evaluated libraries considered here allow a more precise calculation of the neutrino energies (the beta endpoint energy less the mean beta energy). The DDEP library does not include the atomic masses, however the Q-value for each decay is given which can then be summed to give the total energy release. The ENSDF library includes the atomic masses, and the total energy release calculated from the mass differences and the summed Q-values agree. The heat production constants calculated in this work from evaluated nuclear data are given in table 14, with values reported by Birch (1954) [65] and Rybach (1976) [66].

The heat production rates for uranium and thorium are consistent for the three modern evaluations. The differences in heat production constants for ${ }^{40} \mathrm{~K}$ reflect the differences in mean beta energy (see sect. 3.4.2).

\section{Discussion and conclusions}

Nuclear data covering half lives, branching ratios, emission energies and intensities is used to derive parameters used in a wide range of applications. It is essential that this data is accurate, as precise as possible and that practitioners have confidence in the parameters derived from the nuclear data. The use of evaluated libraries provides a convenient means of accessing nuclear data to calculate derived parameters. It is clear that, in some instances, there are significant differences in recommended values produced by different evaluations. Where these occur one or other, or both, of the evaluations must be in error. It is proposed that these differences between evaluations can be used to highlights areas where the evaluations could be improved through better assessment of the primary nuclear data and collection of additional data. By identifying and assessing such variations these data can be used with greater confidence to determine derived parameters in applied work. That such variations exist should be taken as a warning that the outputs of evaluations should not be accepted uncritically. 
Table 15. Summary of differences noted between evaluations.

\begin{tabular}{|c|c|}
\hline Radionuclide & Summary \\
\hline${ }^{234 \mathrm{~m}} \mathrm{~Pa}$ & $1001 \mathrm{keV}$ gamma intensity, agreement between most recent evaluations \\
\hline \multirow[t]{2}{*}{$\left({ }^{238} \mathrm{U}\right.$ series $)$} & but $40 \%$ higher than older evaluations. \\
\hline & Q-value for decay significantly higher in DDEP compared to ENSDF. \\
\hline${ }^{234} \mathrm{~Pa}$ & Significant differences in the mean beta energies. ENSDF and DDEP \\
\hline$\left({ }^{238} \mathrm{U}\right.$ series $)$ & evaluations report total beta intensities $>100 \%$. Beta intensities may need re-examination. \\
\hline${ }^{218} \mathrm{At}$ & De-excitation of $\sim 62 \mathrm{keV}$ level ( $\sim 90 \%$ beta decay branch $)$ not observed. \\
\hline$\left({ }^{238} \mathrm{U}\right.$ series $)$ & Thus, evaluated gamma and conversion electron emissions may be under-estimated. \\
\hline${ }^{214} \mathrm{Bi}$ & Absolute intensity for $609 \mathrm{keV}$ gamma ray, defined by a single high precision data set, \\
\hline$\left({ }^{238} \mathrm{U}\right.$ series $)$ & used to normalise gamma intensity for ${ }^{214} \mathrm{Bi}$ and ${ }^{214} \mathrm{~Pb}$. \\
\hline${ }^{210} \mathrm{Bi}$ & Mean beta energy in DDEP significantly lower than in other libraries, \\
\hline \multirow[t]{2}{*}{$\left({ }^{238} \mathrm{U}\right.$ series $)$} & following a single measurement of the spectral shape. \\
\hline & Other libraries use a generalisation to an allowed transition. \\
\hline${ }^{228} \mathrm{Ra}$ & Single paper reporting an incomplete gamma decay scheme. \\
\hline$\left({ }^{232}\right.$ Th series) & Significant differences in evaluation of beta intensities. \\
\hline${ }^{228} \mathrm{Ac}$ & Incomplete decay scheme, with further coincidence gamma measurements \\
\hline$\left({ }^{232}\right.$ Th series $)$ & recommended in the literature [47]. \\
\hline $\begin{array}{l}{ }^{220} \mathrm{Rn},{ }^{216} \mathrm{Po} \\
\left({ }^{232} \mathrm{Th} \text { series }\right)\end{array}$ & Alpha decay measurements to validate the decay scheme recommended $[48,49]$ \\
\hline \multirow[t]{5}{*}{${ }^{40} \mathrm{~K}$} & Significant variability in half life between evaluations ENSDF, JEFF3.11 and DDEP \\
\hline & all appear to use incorrect shape of the $3 \mathrm{U}$ beta decay. \\
\hline & Use of theoretical $3 \mathrm{U}$ shape boosts mean beta energy by $4.5 \%$ \\
\hline & compared to ENSDF and JEFF3.11, and by $15 \%$ compared to DDEP. \\
\hline & Branching ratios between $\mathrm{EC}$ and $\beta^{+}$decays to ${ }^{40} \mathrm{Ar}$ poorly defined \\
\hline
\end{tabular}

In this paper, differences between three groups of evaluations have been highlighted and examined. These are summarised in table 15 . Of these, the most significant radionuclides for deriving parameters for applications are:

- ${ }^{214} \mathrm{Bi}$ where a single relatively recent high precision data set dominates the newer evaluations producing mean gamma and beta energies that are significantly different from earlier evaluations. It is not ideal that the evaluated nuclear data is heavily dependent upon a single set of measurements. This observation also applies to ${ }^{214} \mathrm{~Pb}$ which also relies on the same single measurement set, although the differences with earlier data are less pronounced.

- ${ }^{210} \mathrm{Bi}$, where JEFF and ENSDF evaluators follow a theoretically unjustified generalisation of calculating forbidden non-unique beta transitions as unique transitions, and DDEP uses a single experimentally measured beta spectral shape.

- ${ }^{228}$ Ac had already been recognised as having an incomplete decay scheme. The decay schemes for ${ }^{228} \mathrm{Ra}$ and ${ }^{234} \mathrm{~Pa}$ are also recognised as being incomplete, and for ${ }^{220} \mathrm{Rn}$ and ${ }^{216} \mathrm{Po}$ the alpha-decay schemes are derived from gamma measurements and additional alpha spectrometry would confirm the derived scheme.

$-{ }^{40} \mathrm{~K}$ has a considerable variation in historic half life measurements, though it is noted that more recent measurements and determinations of half life from geochronometry produce consistent and precise values that suggest that the value in recent evaluations is reliable. Branching ratios between the different decay modes, in particular for the positron and electron capture decays to the ${ }^{40} \mathrm{Ar}$ ground state, remain relatively poorly defined. Most significantly the mean beta $^{-}$decay energy is very poorly defined, with all recent evaluations considered reporting a mean energy for an incorrect shape function. Currently the best measurement of the shape function is from Leutz et al. (1965) [57], and is in close agreement to but not identical with the theoretical 3U shape function.

The resolution of the major uncertainties associated with these data sets would require a comprehensive reevaluation of the existing data, and in most cases the collection of more high precision data. The descriptions of the differences and the underlying literature presented here could form the basis for such a re-evaluation of the existing data, and new data requirements have been identified here. Addressing the deficiency in the LOGFT program, or creation of an alternative code, to directly calculate $\log f t$ values, and associated decay probabilities and branching ratios, and mean energies for $3 \mathrm{U}$ and non-unique transitions would also be beneficial. 
It has been suggested [20] that DDEP represents the best data. On the evidence presented here comparing different evaluations it is evident that generally DDEP and ENSDF are in agreement. Both DDEP and ENSDF benefit from the inclusion of more recent data compared to the earlier JEF2.2 and JEFF3.11 evaluations, however both also include some errors and evaluations based on incomplete decay schemes. The transparency within DDEP is a benefit when assessing the data produced, although there are some points where the evaluators notes are incomplete. Where DDEP and ENSDF differ there are occasions when the DDEP outputs are preferable $\left({ }^{210} \mathrm{Bi}\right.$ where DDEP uses a measured beta spectrum, compared to an incorrect theoretical shape function used by ENSDF), occasions where it is not clear either are better $\left({ }^{228} \mathrm{Ra}\right.$ where both use just a single poor data set), and occasions where both appear to be incorrect $\left({ }^{40} \mathrm{~K}\right.$ where both use, different, incorrect theoretical shape functions for the beta decay spectrum). It is not clear that either evaluation library, as a whole, is preferable, and an approach where the assessment of the choice of data, from either library or other sources, to use is made on a nuclide by nuclide basis may be the best option. For which a comparison between evaluations as conducted here would be essential.

The impact on derived parameters for two applications have been assessed. For conversion factors to calculate dose rate the effects of the different evaluations for ${ }^{210} \mathrm{Bi},{ }^{214} \mathrm{Bi}$ and ${ }^{228} \mathrm{Ac}$ are reflected in gamma and beta conversion factors of the uranium and thorium series, but the most significant impact is the choice of mean beta energy on the ${ }^{40} \mathrm{~K}$ conversion factor. For parameters to calculate geothermal heat production, the differences between evaluations for the uranium and thorium series are small, but again the differences for ${ }^{40} \mathrm{~K}$ as a result of differences in mean beta ${ }^{-}$ decay energy are significant.

Publisher's Note The EPJ Publishers remain neutral with regard to jurisdictional claims in published maps and institutional affiliations.

Open Access This is an open access article distributed under the terms of the Creative Commons Attribution License (http://creativecommons.org/licenses/by/4.0), which permits unrestricted use, distribution, and reproduction in any medium, provided the original work is properly cited.

\section{References}

1. A.D. Carlson, V.G. Pronyaev, R. Capote, G.M. Hale, Z.-P. Chen, I. Duran, F.-J. Hambsch, S. Kunieda, W. Mannhart, B. Marcinkevicius, R.O. Nelson, D. Neudecker, G. Noguere, M. Paris, S.P. Simakov, P. Schillebeeckx, D.L. Smith, X. Tao, A. Trkov, A. Wallner, W. Wang, Nucl. Data Sheets 148, 143 (2018).

2. International Atomic Energy Agency, X-ray and gamma-ray standards for detector calibration, IAEA-TECDOC-619 (IAEA, Vienna, 1991).

3. A.L. Nichols, M. Herman, Report on consultants' meeting on preparation of the proposal for a co-ordinated research project to update $X$ - and $\gamma$-ray decay data standards for detector calibration, IAEA Report INDC(NDS)-378 (IAEA, Vienna, 1998).

4. M. Herman, A.L. Nichols, Update of $X$ - and $\gamma$-ray decay data standards for detector calibration and other applications, IAEA Report INDC(NDS)-403 (IAEA, Vienna, 1999).

5. A.L. Nichols, Appl. Radiat. Isot. 55, 23 (2001).

6. R. Capote, A.L. Nichols, Summary report of consultants' meeting on high-precision beta- decay intensity measurements and evaluations for specific PET radioisotopes, IAEA Report INDC(NDS)-0535 (IAEA, Vienna, 2008).

7. R. Capote, F.M. Nortier, Summary report of consultants' meeting on improvements in charged-particle monitor reactions and nuclear data for medical isotope production, IAEA Report INDC(NDS)-0591 (IAEA, Vienna, 2009).

8. A.L. Nichols, S.M. Qaim, R. Capote, Summary report of technical meeting on intermediate-term nuclear data needs for medical applications: cross sections and decay data, IAEA Report INDC(NDS)-0596 (IAEA, Vienna, 2011).

9. A.L. Nichols, J. Nucl. Sci. Technol. 52, 17 (2015).

10. C.M. Lederer, V.S. Shirley, Table of Isotopes, 7th Ed. (Wiley, New York, 1978).

11. International Atomic Energy Agency, Nuclear Data Services, International Network of Nuclear Structure and Decay Data Evaluators (NSDD), https://www-nds.iaea.org/nsdd/.

12. National Nuclear Data Centre, ENSDF: Evaluated Nuclear Structure Data File Search and Retrieval, http://www .nndc.bnl . gov/ensdf/ensdf/ensdf.jsp.

13. R.B. Firestone, V.S. Shirley, Table of Isotopes, 8th Ed. (John Wiley \& Sons, New York, 1996).

14. Nuclear Energy Agency, The JEF-2.2 Nuclear Data Library, JEFF Report, v. 17 (Nuclear Energy Agency, Organisation for Economic Co-operation and Development, 2000).

15. M.A. Kellett, O. Bersillon, R.W. Mills, The JEFF-3.1/-3.1.1 radioactive decay data and fission yields sub-libraries, JEFF Report 20, NEA No. 6287 (Nuclear Energy Agency, 2009).

16. R.G. Helmer, Nucl. Instrum. Methods Phys. Res. A 422, 518 (1999).

17. R.G. Helmer, E. Browne, M.M. Bé, J. Nucl. Sci. Technol. 39 (sup2), 455 (2002).

18. M.A. Kellett, A.L. Nichols (Editors), Library of Recommended Actinide Decay Data, 2011, STI/PUB/1618 (International Atomic Energy Agency, 2013). 
19. International Atomic Energy Agency, Nuclear Data Services, Decay Data Library for Actinides Including other Heavy Elements, https://www-nds.iaea.org/act_ddl/.

20. A. Pearce, Recommended Nuclear Decay Data, NPL REPORT IR 6 (National Physical Laboratory, 2008).

21. S. Bjornholm, O.B. Nielsen, Nucl. Phys. 42, 642 (1963).

22. H. Xiaolong, W. Baosong, ${ }^{234} \mathrm{~Pa}^{m}$ - Comments on Evaluation of the Decay Data, http://www.nucleide.org/DDEP_WG/ Nuclides/Pa-234m_com.pdf (2011).

23. H. Xiaolong, W. Baosong, ${ }^{234} \mathrm{~Pa}$ - Comments on Evaluation of Decay Data, http://www.nucleide.org/DDEP_WG/Nuclides/ Pa-234_com.pdf (2011).

24. C. Ardisson, J. Dalmasso, G. Ardisson, Phys. Rev. C 33, 2132 (1986).

25. V. Chisté, M.M. Bé, ${ }^{218}$ At - Comments on evaluation of decay data, LNHB/V (2007) http://www.nucleide.org/DDEP_WG/ Nuclides/At-218_com.pdf.

26. V. Chisté, M.M. Bé, ${ }^{214} \mathrm{~Pb}-$ Comments on evaluation of decay data, LNHB/V (2010) http://www.nucleide.org/DDEP_WG/ Nuclides/Pb-214_com.pdf.

27. V. Chisté, M.M. Bé, ${ }^{214} \mathrm{Bi}$ - Comments on evaluation of decay data, LNHB/V (2007) http://www.nucleide.org/DDEP_WG/ Nuclides/Bi-214_com.pdf.

28. E.W.A. Lingeman, J. Konijn, P. Polak, A.H. Wapstra, Nucl. Phys. A 133, 630 (1969).

29. M.A. Hachem, C. R. Hebd. Seances Acad. Sci. Ser. B 281, 45 (1975).

30. J.E. Cline, R.J. Gehrke, L.D. McIsaac, Gamma rays emitted by the fissionable nuclides and associated isotopes, Report ANCR-1069 (Aerojet Nuclear Co., Idaho Falls, Idaho, USA, 1972).

31. W.J. Lin, G. Harbottle, J. Radioanal. Nucl. Chem. Lett. 153, 137 (1991).

32. K.S. Toth, Nucl. Data Sheets 21, 437 (1977).

33. H. Daniel, Z. Naturforsch. 11a, 759 (1956).

34. J.K. Dickens, Energies and Intensities of Gamma Rays Emitted by a ${ }^{226}$ Ra Source, ORNL-TM-3509 (1971).

35. Y.A. Akovali, Nucl. Data Sheets 75, 127 (1995).

36. D.G. Olson, Nucl. Instrum. Methods 206, 313 (1983).

37. U. Schötzig, K. Debertin, Int. J. Appl. Radiat. Isot. 34, 533 (1983).

38. J. Morel, S. Sepman, M. Rasko, E. Terechtchenko, J.U. Delgado, Appl. Radiat. Isot. 60, 341 (2004).

39. V. Chisté, M.M. Bé, M.A. Kellet, ${ }^{210} \mathrm{Bi}-$ Comments on evaluation of decay data, LNHB/V (2014) http://www.nucleide. org/DDEP_WG/Nuclides/Bi-210_com.pdf.

40. A.G. Carles, Nucl. Instrum. Methods Physics Res. Sect. A 551, 312 (2005).

41. X. Mougeot, M.M. Bé, V. Chisté, C. Dulieu, V. Gorozhankin, M. Loidl, LSC 2010, Advances in Liquid Scintillation Spectrometry: Proceedings of the 2010 International Liquid Scintillation Conference, Paris, France, 6-10 September 2010 (2011) pp. 249-257.

42. M. Shamsuzzoha Basunia, Nucl. Data Sheets 121, 561 (2014).

43. H. Behrens, L. Szybisz, Nucl. Phys. A 223, 268 (1974).

44. X. Mougeot, Phys. Rev. C 91, 05504 (2015).

45. A. Luca, ${ }^{228} \mathrm{Ra}-$ Comments on evaluation of decay data, http://www.nucleide.org/DDEP_WG/Nuclides/Ra-228_com.pdf (2009).

46. P.C. Sood, A. Gizon, D.G. Burke, B. Singh, C.F. Liang, R.K. Sheline, M.J. Martin, R.W. Hoff, Phys. Rev. C 52, 88 (1995).

47. A. Pearce, ${ }^{228} \mathrm{Ac}-$ Comments on Evaluation Decay Data, http://www.nucleide.org/DDEP_WG/Nuclides/Ac-228_com.pdf (2010).

48. A.L. Nichols, ${ }^{220} \mathrm{Rn}$ - comments on evaluation of decay data, http://www.nucleide.org/DDEP_WG/Nuclides/Rn-220_com.pdf (2011).

49. A.L. Nichols, ${ }^{216} \mathrm{Po}$ - comments on evaluation of decay data, http://www.nucleide.org/DDEP_WG/Nuclides/Po-216_com.pdf (2011).

50. X. Mougeot, R.G. Helmer, ${ }^{40} \mathrm{~K}$ - Comments on evaluation of decay data, LNHB/INEEL (2009) http://www . nucleide.org/ DDEP_WG/Nuclides/K-40_com.pdf.

51. K. Kossert, E. Günther, Appl. Radiat. Isot. 60, 459 (2004).

52. E.L. Garner, T.J. Murphy, J.W. Gramlich, P.J. Paulsen, I.L. Barnes, J. Res. Nat. Bur. Stand. 79A, 713 (1975).

53. M.O. Naumenko, K. Mezger, T.F. Nägler, I.M. Villa, Geochim. Cosmochim. Acta 122, 353 (2013).

54. K.J.R. Rosman, P.D.P. Taylor, Pure Appl. Chem. 70, 217 (1998).

55. K. Min, R. Mundil, P.R. Renne, K.R. Ludwig, Geochim. Cosmochim. Acta 64, 73 (2000).

56. P.R. Renee, R. Mundil, G. Balco, K. Min, K.R. Ludwig, Geochim. Cosmochim. Acta 74, 5349 (2010).

57. H. Leutz, G. Schulz, H. Wenninger, Z. Phys. 187, 151 (1965).

58. X. Mougeot, BetaShape - Calculs de spectres bêta/Beta spectra calculations, Version 1.0 (2016) available from http://www. nucleide.org/logiciels.htm.

59. A.G. Carles, K. Kossert, Nucl. Instrum. Methods Phys. Res. A 572, 760 (2007).

60. J.A. Cameron, B. Singh, Nucl. Data Sheets 102, 293 (2004).

61. J. Chen, Nucl. Data Sheets 140, 1 (2017).

62. G. Adamiec, M. Aitken, Ancient TL 16, 37 (1998).

63. G. Guérin, N. Mercier, G. Adamiec, Ancient TL 29, 5 (2011).

64. I. Liritzis, K. Stamoulis, C. Papachristosoulou, K. Ioannides, Mediterr. Archaeol. Archaeom. 13, 1 (2013).

65. F. Birch, Heat from radioactivity, in Nuclear Geology, edited by H. Faul (Wiley \& Son, New York, 1954) pp. 148-174.

66. L. Rybach, Pure Appl. Geophys. 114, 309 (1976). 